\title{
Le VIH et les ramifications pour la sécurité alimentaire et la santé infantile dans les communautés affectées
}

\author{
Noel W. Solomons ${ }^{\mathrm{a}} \quad$ Gwen Ellen O'Donnell ${ }^{\mathrm{b}}$ \\ ${ }^{a}$ Centre d'Étude sur l'Altération sensorielle, le Vieillissement et le Métabolisme, Guatemala City, Guatemala; \\ ${ }^{b}$ Project Concern International, Washington, D.C., États-Unis
}

\section{Mots-clés}

Virus de l'immunodéficience humaine $\cdot$ Syndrome d'immunodéficience acquise $\cdot$ Insécurité alimentaire • Sécurité alimentaire $\cdot$ Pays en développement • Agriculture - Aide alimentaire - Infections opportunistes • Pauvreté

\section{Résumé}

Les premiers cas de syndrome d'immunodéficience acquise (sida) dû au virus de l'immunodéficience humaine (VIH) ont été identifiés en 1981. De nos jours, des estimations indiquent que 39 millions de personnes sont infectées par ce virus au plan mondial. Soixante-quatre pour-cent de ces sujets vivent actuellement dans la pauvreté de l'Afrique sub-saharienne, mais la dissémination de la pandémie est actuellement la plus rapide dans les plus grandes nations d'Asie. On admet qu'il y a sécurité alimentaire quand toutes les personnes, à tous les moments, ont accès à des aliments suffisants, sûrs et nutritifs permettant de satisfaire leurs besoins diététiques et leurs préférences alimentaires pour une vie active et saine. Des préoccupations concernant l'insécurité alimentaire apparaissent dans le contexte de la pandémie de $\mathrm{VIH} /$ sida, en raison du principe bien connu de l'interaction entre malnutrition et infection. Les sujets les plus malnutris sont plus sévèrement atteints par des agents infectieux tandis que les ravages de l'infection tendent à épuiser leurs réserves nutritionnelles. Les conséquences sociales et cliniques du VIH/sida mettent en danger l'accès aux aliments dans des zones déjà affectées par la pauvreté et la dégradation de

\section{KARGER}

Fax +4161306 1234 E-Mail karger@karger.ch www.karger.com (c) 2007 Nestec Ltd., Vevey/S. Karger AG, Basel 0250-9644/07/0651-0009\$23.50/0

Accessible en ligne à: www.karger.com/anf l'environnement. Les interventions concernant la productivité agricole, la production de revenus et l'assistance alimentaire doivent être toutes conçues et adaptées aux contextes locaux et communautaires, et reconnues comme nécessaires afin de tempérer les effets nocifs du VIH/sida sur la sécurité alimentaire. L'UNICEF a fait du concept global de soins (caring), défini comme la disposition de temps, d'attention et de soutien au foyer familial et à la communauté afin de satisfaire les besoins physiques, psychiques et sociaux des enfants en croissance et des autres membres du foyer, l'une des composantes de ses efforts visant à favoriser la survie des enfants. Ce domaine inclut des soins destinés aux femmes, des pratiques d'allaitement maternel et d'alimentation des enfants, des soins psychosociaux, la préparation des aliments et des pratiques d'hygiène et de santé au domicile. L'approche de déviance positive, qui consiste à identifier les foyers ayant des comportements de soins dont les résultats sont les meilleurs en termes de croissance, de santé et de développement des enfants, est à présent appliquée dans le contexte des enfants positifs pour le VIH. La stigmatisation est un facteur pernicieux qui tend à isoler les foyers dont des membres sont positifs pour le VIH et qui complique le contexte social dans lequel la sécurité alimentaire et les interventions de soins peuvent être mises en œuvre. Des lacunes persistantes dans nos connaissances des relations entre sécurité alimentaire et $\mathrm{VIH} /$ sida ont été identifiées. Les questions à étudier incluent la véritable efficacité de l'assistance alimentaire afin de tempérer les effets de l'infection à VIH et l'interaction entre l'état de sécurité alimentaire et l'efficacité et la tolérance du traitement antirétroviral. Des études sont cependant 
quelque peu un luxe dans le cadre de l'affectation de ressources financières restreintes, ce qui souligne l'intérêt du recueil et de la codification d'expériences pragmatiques utiles pour les interventions visant à tempérer les effets de l'épidémie, à partir de celles, précieuses, actuellement accumulées sur le terrain par les travailleurs sociaux et les communautés elles-mêmes.

Copyright @ 2007 Nestec Ltd., Vevey/S. Karger AG, Basel

\section{Introduction et contexte historique de la pandémie de sida}

Le 5 juin 1981, les premiers cas cliniques d'une maladie cachectique associée à une mortalité due à des infections, et qui a été appelée plus tard syndrome d'immunodéficience acquise ou sida, ont été décrits chez des homosexuels masculins à Los Angeles [1]. La maladie est transmise par le virus de l'immunodéficience humaine (VIH). Selon des estimations actuelles, la première transmission du virus d'une espèce simienne à l'homme a pu survenir près de 20 à 40 ans plus tôt, formant un réservoir étroitement circonscrit à l'Afrique [2]. L'identification consécutive du sida aux Caraïbes, au Brésil et en Afrique sub-saharienne a alerté la communauté mondiale de la santé publique de l'existence d'une épidémie [3].

L'humanité a souffert d'épidémies tout au long de son histoire. La peste bubonique (peste noire) a décimé jusqu'à un tiers de la population de l'Europe au cours de ses diverses résurgences du XI ${ }^{\text {ème }}$ au XV ${ }^{\text {ème }}$ siècle. Des épidémies fatales de choléra ont également tourmenté l'Europe avant l'ère de John Snow au milieu du $19^{\text {ème }}$ siècle [4]. À l'heure actuelle, le choléra demeure endémique dans certaines parties d'Asie du Sud [5]. La variole a été une pandémie mondiale de l'antiquité jusqu'à son éradication en 1979 [6]. Des pandémies épisodiques de grippe sont survenues, l'exemple le plus dévastateur étant survenu en 1918-1919 pendant la fin de la Première Guerre Mondiale. Au plan mondial, près de 3 millions de personnes ont succombé selon des estimations à cette grande épidémie de grippe.

La mobilité des populations est l'un des facteurs capitaux de la transmission interpersonnelle des maladies. A cet égard, le sida est probablement la première épidémie de l'âge de la mondialisation. Avant l'ère des voyages aériens, se déplacer sur de longues distances était beaucoup plus difficile, et cette mobilité restreinte limitait la dissémination des infections contagieuses. De plus, avant les communications électroniques, la mortalité et les dévastations dues à des épidémies, des famines et des catastrophes naturelles ne parvenaient pas à la connaissance des personnes vivant en dehors des régions atteintes. La population mondiale a augmenté de 2 milliards de personnes au début du $20^{\text {ème }}$ siècle à 9 milliards et plus [7]. De ce fait, les victimes potentielles de maladies transmissibles sont beaucoup plus nombreuses sur l'ensemble du globe. Toutes ces situations sont des facteurs émergents constituant le contexte d'une pandémie contemporaine telle que le sida.
Parmi les 39 millions de personnes infectées par le VIH au plan mondial selon les estimations, plus de 25 millions (64\%) résident en Afrique sub-saharienne. Contrairement à leurs homologues des pays plus industrialisés, les personnes infectées par le VIH en Afrique sont moins à même de bénéficier d'années de bonne santé et de productivité avant la survenue d'un sida. Des millions d'africains sont atteints et meurent prématurément, non en raison de l'absence de médicaments efficaces, mais à la suite de troubles évitables le plus souvent dus à une nutrition insuffisante. Actuellement, le VIH/sida affecte principalement des personnes appartenant au groupe d'âge productif. Cette situation exerce un important impact sur les moyens d'existence et la sécurité alimentaire et nutritionnelle, car elle réduit les forces de travail disponibles [8].

L'impact du VIH/sida sur les enfants et les progrès accomplis dans le domaine de leur survie est également colossal. Selon Walker et Schwartländer [9], le nombre des décès d'enfants de moins de 5 ans dus à l'infection à VIH en Afrique sub-saharienne a augmenté de 2 à 7,7\% de 1990 à 1998. Dans cinq pays, le taux de mortalité imputable au VIH des enfants de moins de 5 ans est de plus de 30 pour 1000 , et dans 16 autres, le taux de mortalité spécifique du VIH des enfants de même âge est de 10 à 25 pour 1000 . Le taux est inférieur à 10 pour 1000 dans le restant des pays africains, soit 18 au total [9]. L'impact du VIH/sida sur la mortalité des enfants de moins de 5 ans en Afrique ne cesse de croître et, s'il n'est pas seule cause, il favorise l'inversion des tendances de la survie des enfants. Selon une étude de l'USAID, le VIH/sida abolit actuellement des années de développement économique et social [10]. La même étude indique que, en 1990, le sida avait été à l'origine de $16,4 \%$ des décès parentaux laissant des enfants orphelins. En 2010, cette proportion aura augmenté à au moins 68,4\%. Ces chiffres sont accablants, mais ne prennent pourtant pas en compte les enfants vivant avec des parents atteints et qui sont les aides principaux de leurs parents, de frères et sœurs plus jeunes et d'autres membres de la famille et sont responsables du maintien des revenus du foyer. Les enfants africains doivent affronter des épreuves d'une étendue et d'une complexité jamais observées auparavant.

Les Nations Unies sont nées le 26 juin 1945 à San Francisco, États-Unis. Avec la création de cette organisation, la pauvreté, la misère et la maladie ne devaient plus être considérées comme des conséquences inévitables de la condition humaine et l'inégalité de la répartition des biens ne devait plus l'être comme appartenant à l'ordre naturel et social. La Déclaration des Droits de l'Homme a été adoptée en décembre 1948 à la Troisième Assemblée Générale des Nations Unies. Sa pertinence pour les personnes vivant avec le VIH/sida a été l'objet d'un commentaire remarqué [11]. Les objectifs du millénaire pour la santé et le développement ont été plus récemment énoncés et plusieurs d'entre eux sont directement pertinent pour le VIH/sida [12].

Il s'agit là de certaines des grandes étapes et du contexte historique qu'a connu le quart de siècle de pandémie de sida. Le centre d'intérêt dans tout domaine sanitaire ne se situe toutefois pas au niveau macropolitique pour la majorité des 
professionnels de santé et des autorités de santé publique. Au contraire, il descend à l'échelon des programmes menés dans des communautés ou à celui de l'implication quotidienne auprès des patients et clients. Nous avons donc considéré qu'il serait intéressant pour les lecteurs des Annales Nestlé de centrer ce numero sur la communauté. «Les aliments, les soins et la santé sont largement reconnus comme la sainte trinité de la nutrition» a commenté Haddad [13] lors du $17^{\text {ème }}$ International Congress on Nutrition en 2001. Dans notre façon de traiter le sujet «Le VIH et les ramifications pour la sécurité alimentaire et la santé infantile dans les communautés affectées», nous tentons d'apporter des aperçus sur les interactions bilatérales entre alimentation et soins globaux dans des communautés pauvres confrontées aux multiples impacts biologiques, sociaux et psychologiques de l'endémie d'infection à VIH.

\section{L'interaction entre nutrition et infection}

Des apports alimentaires inadéquats et des maladies infectieuses sont les causes immédiates les plus importantes de malnutrition [8]. Le VIH/sida étant un complexe associant une infection virale primaire (VIH) à des infections opportunistes (sida), l'interaction entre malnutrition et infection y est fondamentale. Le récent rapport du Département d'État des ÉtatsUnis sur l'alimentation et la nutrition des personnes vivant avec le VIH/sida [14] indique: "L'infection à VIH/sida et la malnutrition sont toutes deux hautement prévalentes dans de nombreuses parties du monde, particulièrement en Afrique sub-saharienne. Ces effets sont intercorrélés et s'exacerbent l'un l'autre dans un cercle vicieux».

\section{Concepts et principes}

Les bases conceptuelles et scientifiques des préoccupations d'ordre biologique ayant trait à l'insécurité alimentaire et à une maladie infectieuse telle que l'infection à VIH ont été déterminées voici près d'un demi-siècle. Scrimshaw et coll. [15] ont documenté d'innombrables interactions entre hôte et agent pathogène dans lesquelles le statut nutritionnel de l'hôte avait conditionné la réponse à une infection et où la présence d'une infection avait influencé le statut nutritionnel de l'hôte. Cet ensemble de données a été étendu en 1968 dans une série de monographies techniques publiées par l'OMS [16]. Un hôte malnutri est plus à même de contracter une infection quand il est exposé à un agent pathogène, ou de présenter une infection plus prolongée ou plus intense qui sera plus probablement fatale. Nous savons maintenant que la base générale de l'effet du statut nutritionnel est liée à l'intégrité et à la fonction du système des défenses immunitaires de l'hôte. L'adéquation du statut en nutriments pourrait influencer le succès des défenses de l'hôte contre l'agent pathogène [17, 18]. Il en est ainsi à chaque niveau, de l'imperméabilité des barrières (peau, muqueuses,

VIH, sécurité alimentaire et santé infantile revêtement intestinal) qui s'oppose à la pénétration d'agents pathogènes, jusqu'à la réponse innée consistant à phagocyter ou à lyser ces agents et à d'autres réponses acquises à type de réactions médiées par anticorps et de réponse inflammatoire systémique.

D’autre part, un animal ou une personne qui a été atteint par une infection, aiguë ou chronique, pourrait présenter une perte de poids et une dégradation générale du statut nutritionnel, ainsi que la survenue de carences vitaminiques ou minérales spécifiques. Il faut noter que le terme classique pour la tuberculose pulmonaire était «consomption». En règle générale, les ravages d'une infection tendent à dégrader le statut nutritionnel de l'hôte en réduisant l'appétit, en bloquant l'absorption des nutriments ou en induisant la destruction ou le gaspillage de nutriments dans l'organisme. Par exemple, une déshydratation aiguë associée à un épisode de gastro-entérite résulte d'une association de tous ces mécanismes. De plus, il est connu depuis longtemps qu'un épisode de rougeole précède souvent la forme la plus sévère de malnutrition protéino-énergétique humaine, le kwashiorkor. Les deux interactions nutrition/infection susmentionnées sont qualifiées de «synergiques».

Réciproquement, dans certaines situations, un hôte trop nourri présente une résistance accrue aux infections, ou est atteint d'infections moins sévères, tandis qu'un hôte trop nourri est davantage sujet à des infections sévères qu'un sujet normalement nourri. Il s'agit là de cas d'interactions nutrition/ infection appelées antagonistes. Dans les années 1950 et 1960, l'obésité et les excès alimentaires n'étaient pas considérés comme d'importants problèmes de santé publique dans les pays industrialisés ou en développement. Bien que la grande majorité des interactions ait été synergique, un certain nombre de relations nutrition/infection a été de nature antagoniste. Ainsi, un déficit en un nutriment a protégé contre une infection ou contre les effets de l'infection par un agent pathogène [15, 16]. Cette situation a été généralement observée avec des agents intracellulaires envahissant les cellules de l'hôte et s'alimentant à partir des nutriments contenus dans le cytosol. Dans ces cas, plus la réserve en nutriments des cellules d'un hôte est riche, plus elle est attractive pour l'agent pathogène, et plus ce germe envahisseur prospère avec succès.

\section{Synergie de l'infection sur le statut nutritionnel dans le $\mathrm{VIH} /$ sida}

La présentation la plus rapide de ce que nous savons sur la progression du sida syndromique constituera un exemple classique des effets nutritionnels indésirables d'une infection, celle du au VIH étant l'affection sous-jacente primaire. Le sida se caractérise par une cachexie [19], et a été appelé «maladie de la maigreur» en langue locale dans les zones du continent africain où il a été décrit pour la première fois. De plus, des infections associées au stade de sida syndromique, dont certaines classiques telles que la tuberculose, ainsi que des infections di- 
tes «opportunistes» (dues à des agents qui ne sont habituellement pas pathogènes pour un hôte normalement nourri), sont pathognomoniques du sida. En raison de l'infection à VIH et de ses infections associées, une personne vivant avec le sida présente une anorexie légère à importante. Par exemple, Cryptosporidium parvum, protozoaire ubiquitaire, qui n'est habituellement pas pathogène pour un sujet immunocompétent (ou, au pire, induit un épisode diarrhéique spontanément résolutif chez les jeunes enfants), provoque une infection intestinale persistante et quasiment intraitable, avec une diarrhé qui peut se traduire par des pertes fécales quotidiennes de deux litres [20]. Le sida est associé à l'activation chronique de la réponse de phase rapide [21], caractérisée par une fièvre et un profil métabolique de consommation et de gaspillage de macro- et micronutriments, entraînant une fonte viscérale et musculaire. Sur la base des effets de déplétion nutritionnelle de l'infection à VIH à tous ces stades, il est essentiel d'apporter des nutriments suffisants et de prendre les mesures nécessaires afin que l'organisme puisse mieux les conserver.

\section{Synergie du statut nutritionnel sur l'infection dans le $\mathrm{VIH} /$ sida}

Sur la base des principes de l'interaction entre nutrition et infection, l'un des premiers espoirs au cours de l'ère du VIH/ sida a été que l'amélioration du statut nutritionnel des populations pauvres et malnutries faciliterait la prévention de la transmission du virus, tant par voie sexuelle [22] que verticalement de la mère au nourrisson [23-25]. La possibilité de pouvoir réduire la transmission sexuelle a été évoquée et examinée, malgré les observations originales indiquant que les homosexuels correctement nourris des pays riches avaient été le fer de lance initial de la pandémie de sida. En règle générale, une supplémentation en vitamines ou en minéraux (micronutriments) pour la prévention de nouvelles infections sexuellement transmises n'a pas donné de résultats positifs. Des aspirations similaires visant à améliorer le statut maternel en micronutriments afin de réduire la transmission du virus de la mère au foetus, au nouveauné ou au jeune nourrisson ont été mises en œuvre par des chercheurs en matière d'interventions sur le terrain. L'article de Downs et Cooper [26] analyse les résultats de ces études.

De plus, certaines associations entre les apports alimentaires en micronutriments spécifiques et la progression de l'infection à VIH au stade symptomatique et au décès [27-30] ont permis de penser que la réduction de carences en micronutriments pourrait atténuer l'infection en réduisant sa progression ou sa mortalité. Le nutriment ayant le plus suscité l'intérêt a été la vitamine A. Fawzi [31] a analysé de façon approfondie tous les aspects des conceptions et résultats d'interventions expérimentales effectuées au cours d'études sur le terrain concernant le statut en micronutriments, la supplémentation en ces substances et l'évolution du VIH/sida.

Une possibilité théorique mais non encore explorée dans la relation complexe entre le VIH et le statut nutritionnel de l'hô- te serait une augmentation de la virulence du rétrovirus. Un modèle de scénario de ce type figure dans les travaux de Beck et coll. [32-35] aux États-Unis. Ces auteurs ont observé qu'un virus de type coxsackie, qui provoque une infection respiratoire transitoire et bénigne chez la souris correctement nourrie, serait transformé par mutation en une souche virulente létale quand elle est transmise à une souris hôte rendue carencée en un oligoélément, le sélénium [32]. De plus, le virus mutant deviendrait alors virulent, induisant des infections fatales chez des rongeurs recevant des apports adéquats en sélénium. Le passage d'autres souches de virus par des hôtes présentant d'autres types de carences en nutriments pourrait également produire des mutations augmentant leur virulence [34]. Avec les carences largement répandues en fer, iode, vitamine A et zinc, entre autres, dans les populations du monde entier, il est urgent de prendre en compte - et d'explorer - tout potentiel de transformation du VIH chez des hôtes carencés en micronutriments.

\section{Antagonisme entre statut nutritionnel et infection dans le $\mathrm{VIH} / \mathrm{sida}$}

Comme tous les virus, le rétrovirus responsable du sida est un agent pathogène intracellulaire. Ce fait peut évoquer la possibilité de certaines formes d'interactions antagonistes dans lesquelles la privation du VIH en un nutriment capital pour son développement et sa prolifération pourrait retarder l'infection. De plus, les infections associées au stade de sida syndromique, dont celles dites «opportunistes», tendent à proliférer en localisation intracellulaire.

Ces hypothèses ont suscité un certain nombre de considérations importantes. L'une d'entre elles serait qu'un renforcement ou une supplémentation systématique en un nutriment pourrait favoriser la prolifération du VIH ou d'autres agents pathogènes invasifs. Dans les communautés affectées par l'endémie de VIH/sida, l'application de programmes à l'échelon d'une population et destinés à améliorer le statut en micronutriments de celle-ci dans son ensemble exercerait-elle un effet mixte? Serait-elle bénéfique pour certains sujets, par exemple séronégatifs pour le VIH et présentant une carence préexistante, mais aurait-elle des effets indésirables pour d'autres, par exemple séropositifs avec ou sans carence en nutriments? La pertinence de ces questions va croissante avec la révélation des résultats observés avec une supplémentation systématique en fer et en acide folique (avec ou sans zinc) chez de jeunes enfants dans une zone d'holoendémie palustre sur l'île de Pemba, Zanzibar, Tanzanie [36]. Les hospitalisations ont tendu à être plus fréquentes et la mortalité plus élevée chez les enfants atteints d'un paludisme dans les deux groupes de traitement contenant du fer et de l'acide folique que chez ceux recevant uniquement du zinc ou non traités (placebo) des groupes témoins.

Le revers de cette question a trait à ce que Weinberg [37] a appelé «immunité nutritionnelle», la protection potentielle 
conférée par un statut nutritionnel marginalement déficient dans un environnement comportant la transmission d'un agent pathogène dépendant de l'état nutritionnel. La connaissance des besoins nutritionnels du VIH pourrait-elle fournir une façon de bloquer la prolifération de ce virus en le privant de nutriments? La personne infectée par le VIH résisteraitelle à des infections opportunistes en recevant moins de nutriments utiles pour la bactérie ou le protozoaire responsable?

Les oligo-éléments susmentionnés (fer et zinc) ont soulevé la question de risques potentiels liés à leur consommation en quantités trop élevées, avec des implications pour la sécurité et la prudence d'interventions au sein de populations avec ces nutriments. En ce qui concerne le fer, un certain nombre de raisons théoriques expliquant pourquoi la diminution des stocks de fer de l'organisme susciterait l'apparition d'agents intracellulaires, tant pathogènes qu'opportunistes, ont été avancées [38]. Un récent essai d'intervention par supplémentation en fer mené au Kenya n'a cependant pas montré un effet indésirable quelconque sur la charge en VIH [39].

Il est établi qu'un grand nombre des mécanismes viraux du VIH dépend du zinc. De plus, les études épidémiologiques de Tang et coll. menés à l'ère précédant le traitement antirétroviral ont observé une progression plus rapide de l'infection à VIH vers un sida [27] et une plus courte survie au cours de la phase de sida [28] chez des sujets de sexe masculin qui consommaient des quantités plus élevées de zinc alimentaire et supplémentaire. Lors d'une récente étude clinique menée à Durban, Afrique du Sud, soulevant certains problèmes éthiques, Bobat et coll. [38] ont testé l'hypothèse selon laquelle l'administration de $10 \mathrm{mg}$ de zinc élément à de jeunes patients atteints d'un sida dans un hôpital de KwaZulu-Natal pendant 6 mois influencerait négativement l'évolution de l'infection. Aucune augmentation de la progression ni mortalité n'a été observée dans le groupe recevant du zinc par randomisation; les réponses observées dans ce groupe ont été en fait bénéfiques. L'autre essai a été publié par Olsen et coll. [39], au Kenya. La charge virale en VIH-1 a été suivie pendant une période de 4 mois durant laquelle des doses bihebdomadaires de $60 \mathrm{mg}$ de fer ont été données à des femmes enceintes séropositives. Aucun effet sur la charge virale de ce traitement martial bihebdomadaire n'a été observé. Considérant qu'une dose quotidienne de 60$120 \mathrm{mg}$ de fer est habituelle en période prénatale, les auteurs ont cependant indiqué que «des effets de doses plus élevées de fer ne peuvent être exclus» [39].

Les résultats de ces essais peuvent être interprétés comme donnant une certaine sécurité quant à l'inclusion d'enfants positifs pour le VIH dans des programmes de supplémentation en fer ou en zinc ou de renforcement du régime alimentaire en ces métaux. Les considérations théoriques ayant trait aux interactions du fer et du zinc avec le VIH ou d'autres agents pathogènes dans le sida syndromique $[39,40]$ militent cependant en faveur d'une vigilance et d'un suivi permanents à la recherche de toute indication contraire aux observations effectuées lors de seulement deux essais.

VIH, sécurité alimentaire et santé infantile
Tableau 1. Déclaration de position de l'American Dietetic Association and Dietitians of Canada sur l'intervention nutritionnelle dans les soins des personnes infectées par le virus de l'immunodéficience humaine

L'infection par le virus de l'immunodéficience humaine (VIH) et la survenue d'un syndrome d'immunodéficience acquise (sida) ont exercé un impact significatif sur des paramètres domestiques et de santé publique, sociaux, politiques et économiques. Les efforts de prévention et de traitement destinés à contrôler l'infection à VIH sont plus exigeants que lors des décennies précédentes. L'obtention de la sécurité alimentaire et nutritionnelle et la prise en charge des complications de l'infection à VIH liées à la nutrition ainsi que des multiples aspects de la maladie instaurée par l'infection à VIH ou entourant celle-ci, appelée VIH-maladie, demeurent d'importants problèmes pour les patients et toutes les personnes intervenant dans les efforts de prévention, de soins et de traitement du $\mathrm{VIH} /$ sida. Les domaines cliniques sources possibles d'erreur concernent les interactions médicamenteuses, une infection conjointe par d'autres germes, des maladies concomitantes, une cachexie, une lipodystrophie et d'autres facteurs.

D’après Fields-Gardner et Fergusson [44].

\section{Sécurité et insécurité alimentaire dans les communautés infectées par le VIH/sida}

En 2001, le Docteur Peter Piot, qui était alors directeur de l'ONUSIDA, a déclaré que la préoccupation majeure pour les personnes vivant avec le VIH/sida qu'il avait visitées était de disposer d'aliments en quantité suffisante [41]. Whiteside et coll. [42] ont souligné une importante réalité concernant les délais, car la longue période d'incubation entre l'infection et la survenue de manifestations cliniques a diverses conséquences. Elle signifie que: «Il faut du temps pour que l'infection à VIH se transforme en sida, et que le sida amène au décès avec toutes ses conséquences, comme les enfants orphelins, la pauvreté et la modification des structures de la population». L'épidémie de $\mathrm{VIH} /$ sida est cependant présente depuis maintenant 25 ans et nous pouvons donc commencer à examiner ses conséquences dans le contexte de son effet sur la sécurité alimentaire des populations affectées. Tabi et Vogel [43], investigateurs infirmiers travaillant au Ghana, ont effectué un constat inhabituel et troublant: «Au Ghana, comme dans de nombreux pays en développement, un plus grand nombre de patients infectés par le VIH et atteints de sida décède de leur mauvais état nutritionnel plutôt que de la maladie elle-même». Bien que provenant des deux pays les plus riches d'Amérique du Nord, le texte de la déclaration de position de 2004 des associations diététiques des États-Unis et du Canada (tableau 1) [44] traduit la prise en compte exhaustive et globale des domaines qui influencent la sécurité alimentaire et les soins des enfants du monde entier au $21^{\text {ème }}$ siècle. 


\section{Définitions de la sécurité alimentaire et mesure de l'insécurité alimentaire}

Selon la Déclaration de Rome et le World Food Summit Plan of Action of the Food and Agriculture Organization, un état de sécurité alimentaire existe «quand toutes les personnes, à tous les moments, ont accès à des aliments suffisants, sûrs et nutritifs permettant de satisfaire leurs besoins diététiques et leurs préférences alimentaires pour une vie active et saine» [45]. Un état "d'insécurité alimentaire» serait une situation dans laquelle les critères susmentionnées ne seraient pas satisfaits. Une définition abrégée est «un accès limité ou incertain à une quantité suffisante d'aliments nutritifs» [46]. Les foyers de préoccupation concernant la sécurité alimentaire peuvent être divers, tant au niveau national, local (communauté) que familial (domicile) et même individuel. Ils sont logiquement liés à la quantité d'aliments disponibles à ces divers niveaux. De plus, avec une répartition inégale de quantités insuffisantes d'aliments, certaines personnes pourraient obtenir leur sécurité alimentaire, mais la généralisation équitable de cette situation à «toutes les personnes» nécessiterait que les aliments disponibles dans un pays soient présents en quantités suffisantes pour couvrir les besoins de tous ses résidents.

Diverses institutions et personnalités ont tenté d'obtenir de mettre au point des définitions opérationelles afin d'évaluer la sécurité alimentaire et de diagnostiquer un état d'insécurité. La FAO (Food and Agriculture Organization) du système des Nations Unies recueille et récapitule des données sur l'équilibre alimentaire dans la plupart des pays, à partir desquelles elle peut déterminer un état de «sous-nutrition» dans une nation, quand le nombre de calories d'énergie alimentaire produite ou importée est insuffisant pour couvrir les besoins de la population. La FAO a généralement insisté sur une définition minimaliste, basée sur la ration minimale essentielle [45]. D’autres ont été plus élaborés et ambitieux dans leurs demandes. Par exemple, Gopalan [47] a commenté: «L'obtention de la sécurité nutritionnelle au niveau du foyer implique l'adéquation des apports en aliments à l'échelon national et une distribution équitable de ceux-ci à la population, conformément aux besoins physiologiques des habitants».

Pour les objectifs les plus pratiques et de recherches dans le domaine du VIH/sida, le niveau du foyer (ou individuel) serait le plus approprié pour la sécurité alimentaire. Les instruments d'évaluation de la sécurité alimentaire sur le terrain remontent au début des années 1990 [48, 49], dont le recueil d'informations sur les caractéristiques démographiques, la fréquence de la consommation de fruits et de légumes et l'approvisionnement du foyer en aliments. Une validation croisée par rapport à d'autres indicateurs d'insuffisance alimentaire dans des foyers ruraux des États-Unis a indiqué des degrés élevés tant de sensibilité que de spécificité du diagnostic d'insécurité alimentaire. Sur un autre front, la diversité diététique est proposée à titre d'indicateur possible de sécurité alimentaire et de facteur prédictif du statut nutritionnel, mais des recherches supplémentaires sont nécessaires afin de normaliser les défi- nitions et la méthodologie avant que ce concept ne puisse être largement appliqué [50]. A ce jour, des outils additionnels de mesure de la sécurité alimentaire au niveau du foyer ont été proposés; ils sont fiables pour des enquêtes basées sur des populations et certaines études ont indiqué que des mesures de la sécurité alimentaire sont associées aux apports en nutriments [51].

Malgré la validation et la validité de la conception de questionnaires à utiliser sur le terrain dans certains contextes, l'évaluation de «l'insécurité alimentaire» n'est pas sans paradoxe. Rose [52] a examiné des indices de sécurité alimentaire sur un échantillon nationalement représentatif de la population des États-Unis et a observé que la plupart des membres des foyers classés comme insuffisants alimentaires (mais curieusement pas les membres d'âge préscolaire des familles) avaient fait état d'apports quotidiens plus bas que ceux des foyers suffisants alimentaires, mais que ce profil ne n'appliquait pas aux membres d'âge préscolaire du foyer. De plus, la prévalence du surpoids augmente chez les enfants. Une plus grande insécurité alimentaire a été associée à un surpoids chez des filles âgées de 12-17 ans, comme mesuré par l'US Food Security Scale [46]. Utilisant le même instrument en Malaisie rurale, tel que validé dans l'État de New York [48, 49], Shariff et Khor [53] ont cependant également enregistré le résultat apparemment paradoxal d'une plus grande fréquence du surpoids et de l'obésité (50\%) chez des femmes exposées à une insécurité alimentaire comparativement à $38 \%$ chez des femmes vivant dans des foyers également exposés à cette insécurité. L'augmentation du tour de taille a suivi la même association.

En conséquence, un mouvement de réforme a récemment eu lieu afin de réviser les objectifs de l'évaluation de la sécurité alimentaire ainsi que la conceptualisation et la mesure de celle-ci [54]. Les aperçus soulignent trois principaux développements conceptuels associés à des approches pratiques de la mesure des contraintes d'accès aux aliments: (1) un moindre emploi des mesures de la disponibilité et de l'utilisation d'aliments pour déterminer un "accès inadéquat», (2) une moindre focalisation sur des mesures objectives pour passer à des mesures subjectives et (3) une insistance croissante sur une mesure fondamentale par opposition à la confiance accordée aux mesures distales et proximales. Webb et coll. [54] ont défini un programme en quatre points (tableau 2) pour le développement et l'amélioration des mesures de la sécurité alimentaire. En raison des éléments paradoxaux des approches traditionnelles résumées plus haut et de sa profondeur conceptuelle plus riche, cette nouvelle approche, une fois développée, semblerait pouvoir offrir plus de promesses et d'applications en relation avec l'impact du VIH/sida.

\section{Vulnérabilité des communautés pauvres}

Les communautés pauvres des pays en développement sont exposées au plus grand risque d'accroissement de l'incidence et de la prévalence du sida $[55,56]$. La pauvreté amène également une vulnérabilité à des apports alimentaires inadéquats, 
une altération du statut nutritionnel et une limitation des soins médicaux $[57,58]$. La transmission du VIH dans ces circonstances fragiles de pauvreté rurale et urbaine a totalement débordé et/ou brisé les mécanismes de résolution des problèmes qui existaient avant l'avènement de la pandémie de sida.

Le VIH et le sida affectent tous les éléments d'une société et pas seulement les personnes directement infectées et vivant avec le virus. Cette infection possède également d'autres caractéristiques spécifiques, comme souligné par Whiteside et coll. [42]: «La longue période d'incubation entre l'infection et la survenue de manifestations cliniques signifie qu'il faut du temps pour que l'infection à VIH se transforme en sida, et que le sida amène au décès avec toutes ses conséquences, comme les enfants orphelins, la pauvreté et la modification des structures de la population. De plus, cette situation signifie qu'une fois que la prévalence de l'infection à VIH aura atteint son pic, il faudra des années avant de pouvoir tempérer l'impact du sida; cette épidémie est un événement à 〈longues ondes`. De ce fait, une perspective intergénérationnelle et portant sur la totalité de la vie est importante afin d'affronter les manifestations locales de la pandémie». Au moins pour l'Afrique, où se trouve le plus grand nombre de personnes vivant avec le VIH/sida, l'insécurité alimentaire est également extrêmement problématique, les prévisions les plus sombres concernant une pauvreté persistante et croissante. Selon Rukuni [59]: «L’Afrique demeure la seule région du monde où le nombre de personnes soumises à la famine s'accroîtra encore en 2020 et où le nombre d'enfants mal nourris augmentera de façon correspondante».

\section{Facteurs conditionnant la sécurité alimentaire des personnes vivant avec le VIH/sida}

Quelles que soient les difficultés et limitations de la mesure précise de l'insécurité alimentaire, les considérations ci-dessous sont une revue des situations et des facteurs présents dans l'environnement et les sociétés qui menacent ou protégent l'accès et la disponibilité aux aliments des communautés. L'intersection entre ces facteurs et des foyers et/ou des sujets infectés par le VIH fera l'objet d'une étude scientifique imminente.

\section{Pertes de capital humain et productivité agricole}

La quantité d'aliments disponibles dans un pays est le produit de l'agriculture et de l'horticulture ou du commerce international. Concernant le commerce, l'aptitude à importer dépend de la richesse générée par les exploitations, qui est une fonction, en retour, des ressources naturelles et humaines converties en biens et services de valeur. Concernant l'agriculture et l'horticulture, l'échelle de production varie de grandes étendues de terrain à de petites zones de subsistance familiale. Quelle que soit cette échelle, le VIH/sida s'est traduit par une série de conséquences nocives pour les activités agricoles. Saasa [60] a mentionné ces conséquences en Afrique (tableau 3).

VIH, sécurité alimentaire et santé infantile
Tableau 2. Besoins en nouvelles recherches sur l'évaluation de la sécurité et de l'insécurité alimentaire

1 Efficacité des mesures de l'insécurité alimentaire au foyer, conçues pour des contextes où cette insécurité est chronique, pour la mise en évidence des processus aboutissant à une insécurité alimentaire aiguë et à une expérience de celle-ci

2 Impact de chocs à court terme, tels que des inondations ou des tremblements de terre majeurs, sur les comportements du foyer qui déterminent des réponses à des questions de sécurité alimentaire

3 Meilleure mesure de l'interaction entre la sévérité et la fréquence des comportements d'insécurité alimentaire au foyer

4 Déterminer si les réponses d'un sujet aux questions d'une enquête peuvent être représentatives des expériences d'insécurité alimentaire de tous les membres du foyer

D’après Webb et coll [54].

Tableau 3. Conséquences de la perte de forces de travail sur la productivité agricole

1 Réduction de l'utilisation des terrains cultivés, car les sujets sont physiquement incapables d'y travailler

2 Réduction du rendement des cultures en raison des délais de réalisation de certaines interventions agricoles telles que des modifications du profil des récoltes

3 Modifications des profils des récoltes, certaines familles étant passées à des cultures demandant moins de travail

4 Diminution de la diversité des récoltes par foyer dans les familles affectées par le sida, ce qui réduit le nombre de végétaux cultivés à un seul de première nécessité

5 Réduction de l'aptitude à contrôler des facteurs nuisibles aux récoltes, par exemple par un désherbage et d'autres mesures entre cultures, en raison d'un manque de main-d'œuvre

6 Perte des connaissances agricoles et des expertises en matière de gestion des fermes, en raison de la disparition d'un ou des deux parents à la suite d'un sida

7 Diminution de l'élevage, car le besoin urgent en argent liquide peut contraindre certaines familles à vendre des animaux

Modifié d'après Saasa [60].

La première conséquence mentionnée au tableau 3, la réduction des ressources humaines en termes de travail et la diminution consécutive de l'utilisation des terrains agricoles, est la plus souvent citée. Comme l'a commenté Rutengwe [8]: «Actuellement, le VIH/sida affecte principalement des personnes de la tranche d'âge productive. Cette situation a une 
forte influence sur les moyens d'existence, les aliments et la sécurité nutritionnelle car elle réduit la main-d'œuvre disponible». Cette main-d'œuvre diminue encore, car les sujets en bonne santé doivent soigner ceux qui sont infectés et assister aux obsèques de ceux qui sont décédés. Les enfants sont dans l'obligation de quitter l'école précocement, n'atteignant ainsi qu'un moindre degré d'instruction. De plus, les décès prématurés de travailleurs adultes entraînent la perte de connaissances indigènes d'une génération à la suivante, ainsi que de l'apprentissage «sur le tas» avec supervision par des personnes plus expérimentées. Selon la FAO des Nations Unies, plus de 7 millions de travailleurs d'exploitations agricoles de 25 pays sub-sahariens sont décédés, et 16 millions supplémentaires devraient périr au cours des deux prochaines décennies.

Le délabrement des forces de travail par le VIH/sida peut nuire aux capacités d'une nation à produire ses propres aliments ou à en importer. Des exemples issus de la littérature récente permettent d'illustrer plusieurs autres conséquences. Dès 1993, à peine 12 ans après le début de l'épidémie de VIH/ sida, une étude rétrospective menée dans les deux districts les plus fertiles de l'Ouganda a documenté une diminution de l'utilisation de terrains agricoles par $66 \%$ des foyers enquêtés, avec des déclins correspondants de respectivement 11 et $32 \%$ de la production de volaille et de bétail, imputés à une mauvaise gestion [60]. Les motifs les plus fréquemment rapportés de réduction du rendement agricole ont été le décès et la maladie; les estimations ont indiqué que cette situation concernait $8 \%$ des familles ayant des enfants de moins de 5 ans dans la zone étudiée. De plus, dans ce contexte, la pauvreté avait diminué l'utilisation de pesticides, d'herbicides et d'engrais [61].

Comme Gillespie et coll. [62] l'ont décrit, la survenue l'épidémie de VIH/sida a eu d'autres conséquences sur l'utilisation des terrains, dont la culture d'espèces moins nutritives (par exemple certains tubercules) qui nécessitent moins de travail. Bien que le fait de ne pas cultiver un terrain le rende plus fertile pour les futures récoltes, en supposant que la famille dispose des moyens pour pouvoir agir ainsi, les familles peuvent devenir plus exposées à la perte des droits sur les terrains, particulièrement les femmes et les orphelins. Un capital naturel et physique est perdu car les familles sont dans l'obligation de vendre des biens productifs (par exemple équipement et outils) et du bétail afin de régler des dépenses médicales et funéraires, rendant quasiment impossible le retour à un travail agricole. De plus, d'autres forces agissent pour nuire à la productivité agricole, comme la surpopulation et la subdivision des terrains par héritage, comme cela a été observé en Ouganda [61].

Dans le domaine voisin de la productivité agricole, les exigences du mode de vie de l'agriculteur, avec des corvées domestiques qui demandent beaucoup de travail et de temps, ont été également identifiées comme un obstacle à la participation des femmes éthiopiennes à un programme d'éducation pour la prévention des maladies sexuellement transmissibles [63].
Domaines ayant trait à l'obtention d'aliments par le foyer familial

Les femmes font partie des forces de travail dans le contexte africain tant rural qu'urbain de l'endémie de sida. Une étude menée chez des femmes mariées au Malawi, au Zimbabwe et en Zambie a examiné les facteurs affectant le statut nutritionnel maternel dans des zones affectées par le VIH/sida et sujettes à la sécheresse [64] et ont permis d'effectuer des observations variables en fonction de la localisation géographique. Le risque de déficit énergétique chronique, tel que défini par un indice de masse corporelle $<18,5 \mathrm{~kg} / \mathrm{m}^{2}$ a été le plus élevé chez les femmes du Malawi disposant de moins de pouvoir de prise de décision familiale, ainsi que chez des femmes vivant dans des zones urbaines en Zambie. Au Zimbabwe, aucune association n'a été observée entre la composition corporelle et le degré de pouvoir décisionnaire. Les auteurs ont conclu que: «Les femmes ayant à la fois de faibles revenus et un déficit énergétique chronique peuvent perdre des capacités de production, ce qui les expose potentiellement à un risque accru d'insécurité alimentaire et de VIH/ sida dans des contextes où la prévalence est élevée» [64].

La sécurité alimentaire au foyer familial peut être compromise par l'insuffisance des ressources et de l'infrastructure financières et par une affectation défectueuse des ressources $\mathrm{du}$ foyer dans les familles pauvres de travailleurs agricoles en Afrique du Sud, même en l'absence d'invalidité parentale [65]. L'insécurité résultante exerce une influence négative, particulièrement sur les enfants, la moitié d'entre eux étant maigres, chétifs ou cachectiques. Ces données proviennent d'une étude ayant souligné les conditions de vie très difficiles de familles de travailleurs agricoles dans des communautés fermières de la province du Nord-ouest d'Afrique du Sud [65], mais ne sont pas atypiques par rapport à des situations présentes dans l'ensemble de l'Afrique sub-saharienne.

La marginalisation sociale et la stigmatisation, vouant des personnes et leurs familles à la discrimination et à l'isolement, sont des facteurs de réduction de la capacité d'un foyer à obtenir des aliments. La stigmatisation du sida varie d'une communauté à une autre et d'une société à une autre [63, 66-70], mais il existe un évitement général des sujets atteints. Même si des sujets disposent de la capacité physique nécessaire à un travail productif, ceux infectés par le VIH et faisant partie des forces de travail font l'objet d'une exclusion différentielle [67], tandis que leurs voisins et clients peuvent se détourner des produits qu'ils produisent eux-mêmes. Dans une société déjà pauvre, les familles vivant directement avec le VIH deviennent les plus pauvres, ce qui restreint leur accès aux sources financières permettant de fournir des aliments et d'autres nécessités de base à la famille [66].

Comme précédemment discuté, les pertes en capital humain sont dévastatrices pour la production agricole. Il en est de même dans le contexte d'une économie de subsistance. La culture de petites étendues individuelles de terrain afin de produire des aliments pour la consommation familiale devient de plus en plus difficile tandis que la santé des membres atteints du foyer se détériore, ce qui affecte gravement leur force et leur 
énergie [71]. Les activités agricoles ne peuvent recevoir l'attention nécessaire et les zones de cultures tombent en jachère.

En sus des pertes en capital humain, naturel et physique, les foyers souffrent également de pertes majeures en capital financier. L'association de situations liées à la stigmatisation dans le domaine du refus de crédits bancaires formels et d'initiatives de microfinances à l'échelon d'un groupe, en sus des difficultés de recrutement de travailleurs journaliers, suscite des contraintes financières additionnelles pour les foyers affectés par le VIH/sida. A titre de mesure désespérée, ces foyers sont dans l'obligation d'emprunter auprès de prêteurs informels à des taux d'intérêt exorbitants [62].

Certaines données d'études de cas sont révélatrices quant aux charges financières qui pèsent sur les personnes vivant avec le VIH/sida. Les dépenses du foyer imputables au sida jusqu'au décès ont été de USD 836 par cas selon une publication de Chad en 2004 [72]. Les dépenses liées aux pertes de productivité ont représenté jusqu'à $28 \%$ des coûts totaux. Plus de la moitié des coûts totaux (56\%) étaient des dépenses médicales, les frais d'obsèques contribuant pour $16 \%$. Les personnes atteintes d'un sida ont eu plus souvent recours à l'emprunt et à la vente de biens domestiques que les témoins pour financer leur traitement. Les dépenses des foyers des patients atteints d'un sida ont été beaucoup plus élevées que celles des foyers témoins, principalement en raison de débours liés à l'état de santé.

\section{Domaines concernant les foyers familiaux en matière}

d'alimentation du nourrisson et du jeune enfant

En termes d'alimentation du nourrisson et du jeune enfant, et bien qu'il n'existe aucun coût monétaire apparent du lait maternel, les besoins énergétiques des mères allaitantes augmentent d'environ $500 \mathrm{kcal}$ comparativement à ceux des femmes non enceintes et non allaitantes du même âge [73]. Aucun besoin supplémentaire lié à l'allaitement et allant au-delà de la demande corrigée en fonction de la présence d'une infection à VIH n'a été établi [74], mais, si la disponibilité de calories pour l'alimentation de base est déjà un problème, l'obtention d'aliments supplémentaires pour permettre la prise des $500 \mathrm{kcal}$ additionnelles pour l'allaitement peut représenter le «point de rupture» pour l'équilibre financier d'un foyer.

Si l'obtention d'aliments supplémentaires est difficile pour les mères, l'achat d'aliments spéciaux pour le nourrisson est encore plus prohibitif. Dans les communautés les plus pauvres, des formules artificielles adéquates peuvent ne pas être commercialisées et, si elles le sont, peuvent ne pas être accessibles et financièrement abordables pour les foyers choisissant cette option en réponse à une infection maternelle à VIH [75]. Si une mère choisit de ne pas adopter l'allaitement au sein et de le remplacer par une alimentation par substituts du lait maternel, les coûts combinés des formules pour nourrissons et des fournitures nécessaires représentent une charge substantielle pour les ressources du foyer. En raison des difficultés sanitaires, la sécurité d'emploi de formules préparées dans des situations précaires d'hygiène est une préoccupation supplémentaire [76], laissant prévoir davantage d'épiso-

VIH, sécurité alimentaire et santé infantile des diarrhéiques chez les enfants. Cette situation impose de plus grands efforts pour le soin des enfants, l'achat de médicaments et un risque accru de mortalité infantile, s'ajoutant au «coût» global de l'absence d'allaitement maternel. Enfin, tout investissement particulier dans des formules destinées au nourrisson limite les ressources disponibles pour l'alimentation de la fratrie plus âgée.

La fourniture «d'aliments de sevrage» est le stade suivant de l'évolution alimentaire de l'enfant, dans laquelle la sécurité alimentaire peut intervenir. Les régimes alimentaires offerts aux nourrissons dans les foyers pauvres afin de compléter ou de remplacer le lait maternel sont monotones et volumineux et couvrent rarement les lacunes dues à l'absence de lait maternel en matière d'apport de l'énergie et des nutriments nécessaires à une croissance rapide, à la constitution de stocks de nutriments et à l'assurance d'une résistance aux infections [50]. Le profil de croissance et la prévalence de la malnutrition observée de la naissance jusqu'à l'âge de 5 ans en Afrique sub-saharienne sont évocateurs d'une inadéquation de l'alimentation en nutriments et de la survenue d'infection.

\section{Consommation alimentaire des personnes et communautés} vivant avec le $\mathrm{VIH} /$ sida

Les domaines de la consommation alimentaire ayant trait à l'insécurité des aliments et au métabolisme biologique sont multiples. Les résultats d'enquêtes sur l'adéquation alimentaire ont varié en fonction du contexte. Par exemple, à Boston, Massachusetts, États-Unis, l'adéquation alimentaire des macro- et micronutriments, sur la base d'une évaluation quantitative d'enregistrement de l'alimentation pendant 3 jours, a été généralement acceptable chez des toxicomanes par voie intraveineuse positifs ou négatifs pour le VIH; aucune distinction n'a pu être effectuée entre les deux sous-groupes [77]. L'équivalence des apports peut toutefois ne pas être suffisante en raison d'une non-équivalence documentée des demandes en nutriments. Selon l'OMS [73], les besoins énergétiques des sujets positifs pour le VIH sont plus élevés de $10 \%$ afin de maintenir le poids corporel et l'activité physique, tandis que ceux des sujets présentant une infection symptomatique sont plus élevés de 20 à $30 \%$ afin de permettre le maintien du poids adulte. Le plus bas indice de masse corporelle des groupes positifs pour le VIH a été davantage attribué aux demandes métaboliques liées à la maladie qu'à des facteurs de restriction alimentaire [77]. Chez les enfants, les besoins en énergie supplémentaire pourraient être de 50 à 100\% afin de regagner le poids perdu [73].

De plus, une nouvelle étude publiée par HIV Medicine a montré qu'une malnutrition au moment de l'instauration d'un traitement antirétroviral était associée à une survie significativement plus courte. La mortalité des patients malnutris est six fois plus élevée que celle des patients correctement nourris [78]. Le VIH et la malnutrition œuvrent ensemble dans un cercle vicieux qui affaiblit le système immunitaire et l'organisme par l'intermédiaire d'infections réitérées. 
Les apports alimentaires ne sont toutefois pas sans aspects paradoxaux chez les patients infectés par le VIH. Kim et coll. [79] ont mené une enquête dans une population d'adultes infectés par le VIH aux États-Unis. Vingt-trois pour-cent suivaient un régime alimentaire afin de perdre du poids. Les sujets non Blancs et les toxicomanes par voie intraveineuse ont consommé moins d'énergie que les Blancs et les sujets n'utilisant pas de drogue par voie intraveineuse. Les femmes exemptes de nausées et de vomissements ont consommé plus d'énergie. Une proportion significative de sujets de la cohorte de l'étude (52\%) consommait une quantité de vitamine A inférieure à l'apport alimentaire recommandé et les apports protéiques étaient inadéquats chez $11 \%$. La littérature actuelle sur les apports alimentaires est manifestement centrée sur les pays riches, et des observations plus empiriques provenant de pays en développement sont nécessaires.

\section{Mythes et paradoxes de la relation entre insécurité alimentaire et $\mathrm{VIH} /$ sida}

Divers mythes et paradoxes concernent le domaine de l'insécurité alimentaire et du VIH/sida. Il est important de les reconnaître et de ne pas leur permettre de perturber les politiques et programmes.

\section{Prendre en compte les mythes}

Il est établi que des situations de conflits, comme par exemple en Côte d'Ivoire, perturbent gravement le système de santé et interfèrent avec les efforts de prévention de la transmission du VIH et de soins des personnes infectées [80]. Que signifie insécurité alimentaire pour la transmission de la maladie? Dans une analyse du Haut Comité des Nations Unies pour les Réfugiés, Spiegel [81] affirme que: «Les conflits, les déplacements de populations, l'insécurité alimentaire et la pauvreté rendent les populations atteintes plus vulnérables à la transmission du VIH. Toutefois, le point de vue fréquent selon lequel cette vulnérabilité se traduit nécessairement par un plus grand nombre d'infections à VIH et, en conséquence, alimente l'épidémie de VIH/sida, n'est pas conforté par des données». S'il en est ainsi, résoudre les problèmes d'insécurité alimentaire qui sont le sujet de la présente analyse pourrait être nettement palliatif, tempérant les souffrances des sujets infectés. Cette résolution ne contribuerait toutefois pas à l'arrêt des progrès de la transmission virale elle-même.

\section{Affronter les paradoxes}

Comme discuté plus haut, des mesures de l'insécurité alimentaire au foyer familial peuvent être associées à une obésité. De même, malgré l'image de «maladie de la maigreur» du sida, des facteurs environnementaux, comportementaux et pharmacologiques peuvent favoriser des états de surpoids. Dans les régions urbaines d'Afrique, le surpoids pourrait actuellement devenir le contexte de l'extension du VIH/sida. L'étude sur la transition et la santé au cours de l'urbanisation des Sud-afri- cains a montré que l'urbanisation de la province Nord-ouest d'Afrique du Sud s'était accompagnée d'une amélioration des apports en micronutriments et du statut vis-à-vis de ceux-ci, mais également d'un accroissement de la fréquence du surpoids, de l'obésité et de plusieurs facteurs de risque de maladies non transmissibles [82]. L'émergence croissante de maladies non transmissibles chez les Sud-africains noirs, combinée à la pandémie de VIH/sida, est une situation complexe pour les travailleurs sociaux et les politiciens [83].

Le facteur est l'élargissement de l'accès des personnes les plus défavorisées au traitement anti-VIH. Les effets indésirables de certains traitements de l'infection à VIH et les maladies infectieuses associées à celle-ci accroissent le risque de survenue d'un diabète, d'une obésité et d'un syndrome métabolique. A ce titre, les traitements doivent être attentivement choisis, particulièrement quant au risque cardiovasculaire [84]. Des chercheurs de Philadelphie, États-Unis [85], ont émis l'intéressante hypothèse suivante: (1) l'obésité prédispose au diabète et aux affections cardiovasculaires et (2) il s'agit également des complications associées à l'infection à VIH et/ou à son traitement. Ces auteurs ont observé que, à l'ère thérapeutique, une obésité (14\%) et un surpoids (31\%) étaient plus fréquents qu’une cachexie $(9 \%)$ dans leur population clinique à Philadelphie [85]. Dans le sous-groupe des femmes, la prévalence de l'obésité était de $28 \%$. La prévalence d'une obésité centrale a été de $45,7 \%$ dans un groupe de personnes recevant un traitement antirétroviral hautement actif afin de contrôler une infection à VIH à Sao Paulo, Brésil, et a été associée à une plus grande consommation de lipides; pour chaque augmentation de $10 \mathrm{~g}$ des apports en lipides, les risques d'obésité centrale ont augmenté de 1,3 fois [86].

\section{Réponses politiques et des programmes à l'insécurité alimentaire affectant les personnes vivant avec le $V I H /$ sida, leurs familles et leurs communautés}

Rosegrant et Cline [87], dans leur article très remarqué paru dans Science en 2003, ont commenté: «La sécurité alimentaire globale demeurera une préoccupation mondiale pendant les 50 prochaines années et au-delà. Le rendement des récoltes a récemment diminué dans de nombreuses zones en raison d'une réduction des investissements en recherches et en infrastructures, ainsi que d'une raréfaction supplémentaire de l'eau. Le changement climatique et le VIH/sida sont également des facteurs capitaux affectant la sécurité alimentaire dans de nombreuses régions». Le groupe de consultants de l'OMS sur les besoins nutritionnels des personnes vivant avec le $\mathrm{VIH} /$ sida a souligné un «besoin urgent d'un renouvellement de l'intérêt pour les ressources pour la nutrition et l'utilisation de celles-ci comme partie fondamentale de l'ensemble exhaustif des soins au niveau du pays» [74]. La sécurité alimentaire s'altère quand des systèmes alimentaires sous-jacents sont soumis à des contraintes [88]. Les «points de rupture» sont notamment des éléments de modification de l'environnement, dont des situa- 
tions de conflit et le VIH/sida. Cette situation peut être particulièrement sévère quand plusieurs facteurs s'associent, par exemple dans le sud de l'Afrique au cours de la dernière décennie. Il est donc important de prendre en compte les aspects de l'insécurité alimentaire au niveau global, national et communautaire ainsi qu'à celui du foyer et de l'individu dans le contexte de la pandémie de VIH/sida.

\section{Considérations de politique générale pour la réduction de} l'insécurité alimentaire

Les choix des politiques et des opérations des programmes devraient de plus en plus être basés sur des preuves de leur efficacité, de leur sécurité et de leur efficience, mais la recherche de ces démonstrations n'a satisfait personne à ce jour. Le rapport du Département d'État des États-Unis commente: «Malgré un nombre croissant d'interventions destinées à éliminer l'insécurité alimentaire dans des contextes où la prévalence du VIH/sida est élevée, il existe peu de démonstrations expérimentales de l'efficacité de ces programmes pour l'amélioration de la nutrition et de la santé des populations cibles ou pour un accès durable de celles-ci aux aliments» [14]. Le contexte et l'expérience convainquent cependant rapidement que la recherche de mesures généralisables peut être futile et que, comme les politiques, la plupart des recommandations visant à faire face au VIH/sida sont locales.

Gillespie [89] a résumé les trois principes prioritaires et directeurs d'une stratégie exhaustive dirigée contre l'insécurité alimentaire apparaissant dans le contexte du VIH/sida: (1) le renforcement de la résistance des foyers familiaux et de la communauté au VIH et au sida; (2) le soutien et l'amélioration des opportunités d'accroissement des revenus dans les communautés affectées, et (3) l'assurance d'une protection sociale appropriée. Cet auteur prévient toutefois que la mobilisation ne doit pas être distincte et spécifiquement dédiée à la crise liée au VIH/sida, mais doit plutôt construire les solutions sur l'ensemble des communautés. Saasa [60] propose une philosophie transversale similaire en appelant à résoudre les problèmes sous-jacents que sont la pauvreté et la stagnation du développement dans les zones rurales des pays affectés, particulièrement en Afrique sub-sahari-enne.

Selon Gillespie et coll. [71], les principes politiques sont les suivants: affectation ciblée des ressources, attention portée à l'étendue et à l'échelle, collaboration avec des partenaires adéquats, planification et programmation face à des urgences superposées, et suivi et évaluation. Concernant les interventions ayant spécifiquement trait à la sécurité alimentaire dans le cadre de l'épidémie de VIH/sida, la priorité à établir est un renforcement dirigé dans les secteurs de l'agriculture, des jardins familiaux et communautaires, de l'aide alimentaire, de l'assainissement de l'eau, de la santé environnementale et de la gestion des ressources naturelles basée sur la communauté $[90,91]$.

De ce fait, un centrage concerté sur la pauvreté et l'inégalité dans les sociétés affectées par le VIH/sida permettra de prendre en charge les conséquences de l'infection. Gillespie
$[90,91]$ qualifie ce projet de «fil directeur» dans la lutte contre le $\mathrm{VIH} /$ sida, car permettant par son action de résoudre les problèmes de la communauté. Il s'agit d'une des tactiques permettant d'agir efficacement sans stigmatiser les bénéficiaires. Elle peut être perfectionnée en fournissant des capacités appropriées et en incitant à leur application par des motivations raisonnables [90, 91].

\section{Soutien et développement agricoles afin de tempérer}

l'insécurité alimentaire

$\mathrm{Au}$ sens le plus large, une intervention agricole inclurait les jardins familiaux et communautaires ainsi que la culture et l'élevage afin d'apporter à la fois des revenus et un soutien nutritionnel. L'horticulture est centrée sur la diversité alimentaire et l'enrichissement de l'alimentation par des micronutriments essentiels. Le jardinage pouvant être une nouvelle activité pour une communauté, des efforts doivent être consacrés à la construction d'une capacité communautaire à cultiver des jardins ainsi qu'à l'induction de modifications du comportement attirant l'attention sur la nécessité de consommer les aliments riches en nutriments produits localement.

Une agriculture de subsistance peut être maintenue si des cultures ne nécessitant que des soins minimaux ou des mesures d'économie du travail, telles que l'introduction d'animaux afin de labourer les sols, viennent remplacer les méthodes traditionnelles [71]. La diversification de la production et l'introduction de technologies agricoles réduisant le recours au travail ou des goulots d'étranglement (par exemple absence de labourage) faciliteront également la réduction du fardeau pesant sur le capital humain. Il est également possible de réduire la charge liée au travail par l'introduction de technologies appropriées, telles que des méthodes de traitement des aliments à petite échelle et économisant du travail, des fourneaux efficaces consommant peu de combustible et des pompes à eau. L'amélioration et l'adaptation des systèmes agricoles par une recherche et un développement appropriés au contexte ont été proposées par Parley et coll. [92] comme moyen de rendre les pays moins dépendants et les communautés plus résistantes. Ces auteurs appellent à des investissements dans de nouvelles technologies adaptées à la production d'aliments dans les pays en développement. Des options de microfinances peuvent également être introduites afin de permettre des dépenses opérationnelles permettant de financer l'acquisition d'animaux résistant à la sécheresse, divers apports, l'embauche de travailleurs, etc. Les communautés doivent également être incitées à partager leurs connaissances et expériences pratiques en matière d'agriculture avec les veuves, les orphelins et les autres survivants, ainsi que d'inclure une formation à l'agriculture dans le cursus scolaire.

\section{Assistance alimentaire directe afin de réduire l'insécurité alimentaire}

Le principal argument qui milite en faveur de l'assistance alimentaire est lié aux principes humanitaires consistant à apporter assistance aux personnes malnutries. Dans les zones 
Tableau 4. Options du Programme Alimentaire Mondial pour l'utilisation de l'aide alimentaire afin d'atténuer l'épidémie de VIH/sida

1 Vivres pour la formation professionnelle des enfants des rues et orphelins

2 Alimentation à l'école avec des rations spéciales à emporter au domicile pour les familles s'occupant d'orphelins

3 Programme «Vivres contre formation» favorisant des activités productrices de revenus (culture de champignons, batik, etc.) et liés à des facilités de crédit à petite échelle pour les femmes et les autres orphelins

4 Programme «Vivres contre formation» et «Vivres contre travail» afin de soutenir les agriculteurs par des schémas de traction animale et la fourniture de graines et d'outils agricoles

5 Programme «Vivres contre travail» dans le but de soutenir l'accroissement de la production agricole par la création de jardins familiaux afin d'améliorer la diversification alimentaire et d'augmenter les apports en micronutriments

6 Programme «Vivres contre travail» et «Vivres contre formation» afin de soutenir l'introduction d'activités rémunératrices à petite échelle et demandant peu de travail dans le but (a) d'augmenter les apports en aliments hautement énergétiques et protéiques et (b) de procurer des économies et un capital qui augmenteront au cours du temps

Modifié d'après Gillespie et coll. [71] tel qu'adapté du Programme Alimentaire Mondial [94].

où le traitement antirétroviral est difficilement accessible, compenser les déficits nutritionnels aurait un net bénéfice palliatif, comme l'ont résumé Tabi et Vogel [43]: «Le statut sanitaire et nutritionnel des patients peut être amélioré par des aliments nutritifs, leur permettant une vie plus longue et de meilleure qualité». Le soutien nutritionnel est considéré comme pouvant prolonger la vie des sujets, tant pour leur propre bénéfice que pour les personnes dépendant de leurs soins [71].

L'aide alimentaire directe a longtemps été considérée comme le «sujet tabou» de l'aide au développement par certains auteurs soutenant qu'elle tend à créer une dépendance et à perturber les marchés agricoles. La réalité du VIH/sida dans les pays pauvres est cependant qu'il a déjà créé cette dépendance et ces perturbations. La question est donc de savoir comment utiliser au mieux l'aide alimentaire afin de tempérer les effets de l'épidémie. Kadiyala et Gillespie [93] ont récemment analysé de façon détaillée le potentiel de l'assistance alimentaire. Ils l'ont placée au tout premier plan dans un réseau de sûreté sociale. Comme l'a reconnu le Département d'État des ÉtatsUnis: «Les interventions d'aide alimentaire peuvent exercer une influence positive sur la vie des bénéficiaires en réduisant leur dépendance à des stratégies d'affrontement dangereuses et érodant leurs moyens d'existence et en améliorant la diversité et la qualité de l'alimentation ainsi que la sécurité alimentaire au foyer familial» [14]. Rukuni [59] a aiguillonné les gouvernements de façon semblable en demandant des politiques complémentaires de sécurité alimentaire qui augmentent la probabilité que des aliments soient accessibles à des groupes vulnérables.

$\mathrm{Si}$, de fait, l'assistance alimentaire directe est une composante utile d'un réseau de sûreté, des pièges et de la créativité entrent en jeu pour sa mise en œuvre. L'assistance alimentaire doit généralement cibler les zones d'un pays où l'insécurité alimentaire est maximale et dans lesquelles les foyers familiaux ne peuvent pas parvenir à satisfaire leurs besoins alimentaires [71]. L'organisation de la distribution d'aliments doit de plus éviter de saper les stratégies de résolution des problèmes et de développement des familles et de la communauté [71]. Dans une des premières analyses [71], les idées du Programme Alimentaire Mondial [94] pour l'incorporation de l'aide alimentaire à titre d'assistance afin d'obtenir des résultats en termes d'éducation et de productivité (tableau 4), tout en soutenant la nutrition des personnes insuffisamment nourries, ont été mises sous la loupe de l'épidémie à VIH. Plus récemment, Kadiyala et Gillespie [93] ont été amenés à considérer l'assistance alimentaire en termes du contexte plus large de protection des moyens d'existence. Apparemment, il existe une ouverture croissante pour l'exploration de l'utilisation de plus en plus imaginative de l'aide alimentaire. Les communautés sont des entités sociales complexes. Une précaution est cependant d'éviter le ciblage visible des bénéficiaires, quand une stigmatisation est liée à ce besoin [95], ce qui est généralement le cas avec l'infection à VIH. Finalement, toutefois, il y a ceux qui chantent le refrain familier selon lequel l'aide alimentaire doit inclure une «stratégie de sortie» afin d'éviter une dépendance permanente [14].

\section{Principes de la programmation d'interventions au niveau local}

Il existe des critiques insistantes de l'échelle limitée des programmes existants telles que: "Quand des organisations ont mené des interventions afin d'améliorer la sécurité alimentaire dans les zones d'endémie de VIH/sida, les projets ont tendu à être isolés et à petite échelle et les résultats non généralisables» [14]. En partie, peut-être, ces programmes sont trop petits pour tenter de suivre les recommandations prudentes de les centrer sur les zones existantes d'insécurité maximale [8, 71]. Ils sont isolés car les communautés les plus atteintes le sont également, tant par l'éloignement géographique que par la stigmatisation sociale. Toutefois, si les principes consistant à donner du pouvoir et de la responsabilité à la communauté sont opérationnels, les interventions ne seront pas des «protocoles» car les communautés trouveront leur chemin dans des circonstances particulières qui sont, simultanément, des circonstances changeantes.

Dans leur traité sur la sécurité alimentaire globale, Rosegrant et Cline [87] soulignent les droits de l'homme fondamen- 
taux des communautés à participer à toutes les étapes du ciblage des programmes, droits élémentaires pour un bon gouvernement démocratique. L'importance du développement d'un programme local, synthétisant les complexités particulières d'une communauté afin de mettre en action des recherches opérationnelles, a été également soulignée par Rutengwe [8]. Son étude a montré que l'interaction entre insécurité alimentaire chronique au foyer familial en milieu urbain, prévalence de la malnutrition et insuffisance des revenus était le problème majeur. L'étude a également montré qu'une démarche interactive, utilisant des algorythmes de problème et de solution, par exemple, afin d'analyser logiquement les causes et effets de la situation dans une zone donnée, a fourni un moyen utile de formuler des actions locales avec un apport maximal des décisionnaires de la communauté.

\section{A la recherche de solutions lors de l'African Forum 2006}

Les principes théoriques et les observations scientifiques nous donnent peu de solutions pratiques pour les communautés et les sujets confrontés à l'insécurité alimentaire. Un exemple des étapes pragmatiques en cours entreprises afin de recueillir des leçons sur le terrain en partageant l'expérience de professionnels de santé en première ligne a été une réunion qui s'est tenue à Lusaka, Zambie, en mai 2006, proposée et coordonnée par le Project Concern International. Intitulé «The African Forum 2006: An Integrated Response to the Dual Epidemic of HIV/AIDS and Food Insecurity» (le Forum Africain 2006: une réponse intégrée à la double épidémie d'infection à VIH/sida et d'insécurité alimentaire) [96], le forum a cherché à donner aux participants la possibilité de partager des expériences de première main acquises dans l'affrontement des problèmes difficiles de la double épidémie et dans la conception et la mise en œuvre de programmes intégrés. Au cours de la semaine, les participants ont partagé leurs expériences et ont appris des solutions pratiques pour l'amélioration de la sécurité des aliments et des moyens d'existence dans leurs propres communautés. Les participants ont également identifié des priorités et des modifications nécessaires à tous les niveaux afin de transformer en réalité un programme intégré de sécurité alimentaire et de lutte contre le VIH/sida. Ces idées et observations de première ligne sont présentées dans la Déclaration du Forum Afrique 2006.

Le forum a cherché à développer les aptitudes du personnel sur le terrain dans le domaine des programmes intégrés en facilitant l'apprentissage auprès de pairs ainsi qu'en motivant les praticiens et en leur donnant du pouvoir par des exemples concrets de réponses réussies de communautés aux problèmes de la double épidémie de VIH/sida et d'insécurité alimentaire. L'apprentissage a reposé sur les principes de l'éducation des adultes et des modifications du comportement. Les apprenants adultes doivent activement s'engager afin que l'apprentissage s'effectue, se construisant sur ce qu'ils connaissent déjà. Il en est particulièrement ainsi pour les équipes sur le terrain, qui sont des personnes d'action, nécessitant des approches d'apprentissage dynamiques, transmises et orientées sur les com- pétences. Au cours de l'African Forum, chaque participant devait être à la fois un apprenant et un contributeur. Ainsi, chaque participant devait être présent sous une forme ou sous une autre, et s'engager activement dans des activités d'apprentissage par transmission sur un aspect particulier des programmes intégrés de lutte contre le VIH/sida et de sécurité alimentaire et nutritionnelle. Les participants ont appris en «mettant la main à la pâte», par exemple en bêchant des jardins, en préparant des aliments et en visitant des projets communautaires.

Le forum [96] a abordé les difficultés pratiques auxquelles les conseillers sont confrontés dans la mise en œuvre des meilleures pratiques pour l'alimentation des nourrissons et jeunes enfants, par exemple. Les obstacles spécifiques à l'adhésion aux protocoles d'allaitement maternel exclusif et de sevrage rapide sont la stigmatisation et le coût. En Zambie, des jardins communautaires ont été créés afin d'améliorer la qualité des aliments, au-delà de la simple satisfaction des besoins en énergie, en accord avec les préoccupations plus larges soulignées par Gopalan [47]. Divers projets d'horticulture ont été illustrés au forum, manifestant les potentiels multiples de la sécurité alimentaire, d'amélioration de la nutrition et d'accroissement des moyens d'existence. Un exemple de cet objectif holistique et synergique est un projet du Malawi, «Améliorer les moyens d'existence par l'amélioration des aliments», qui associe un programme de sécurité alimentaire à des composantes environnementales, éducatives et sanitaires au niveau des foyers familiaux dans les communautés affectées par le VIH [96]. Étendant le concept d'intégration à une synergie avec des initiatives naissantes de traitement médicamenteux, le forum est parvenu à un consensus selon lequel la participation à des initiatives de traitement médicamenteux sans aliments quantitativement et qualitativement adéquats ne prolongeait que peu de vies [96].

Lors du forum [96], l’agriculture elle-même a été envisagée dans un contexte intégré, avec des expériences de cultures de produits permettant de partager les revenus générés. En Zambie, des groupes de veuves se sont réunis afin de cultiver des champignons pour les commercialiser, dans le but d'accroître la sécurité alimentaire au foyer. L'apiculture pour production de miel a été une autre activité génératrice de revenus parmi celles illustrées, comme l'a été l'élevage.

Les problèmes de sécurité alimentaire ne peuvent être tous résolus au niveau agricole. Des «réseaux de sécurité» d'agences gouvernementales et non gouvernementales, qui peuvent intervenir dans des transferts monétaires et la distribution d'aliments aux familles luttant pour leur vie, sont considérés comme appartenant à une solution intégrée. Comme noté, Marchione [95] a admonesté les responsables des programmes afin qu'ils tentent d'éviter les pièges d'une assistance ciblant spécifiquement des membres de la communauté, tant pour la stigmatisation pouvant marquer ces bénéficiaires que pour le ressentiment pouvant apparaître dans des segments de la population n'ayant pas droit au programme. 
Tableau 5. Les six catégories de pratiques de soins

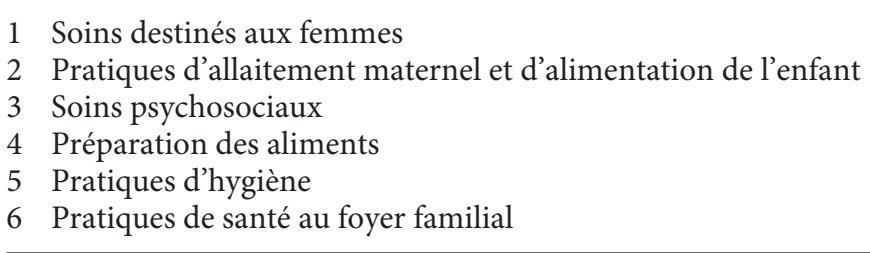

D’après Martin-Prevel [97].

\section{Soins et prise en charge pour la santé de l'enfant}

\section{Prise en charge des enfants et pratiques traditionnelles de santé}

La santé des enfants, tant infectés que non infectés par le $\mathrm{VIH}$, et tant orphelins que vivant avec leurs parents, dépend non seulement de la sécurité alimentaire et nutritionnelle, mais encore de la qualité des soins globaux qu'ils reçoivent. Ces soins, à leur tour, sont fonctions des ressources disponibles dans la communauté et au foyer familial (dont énergie et temps), du comportement de prise en charge de l'enfant par les aidants et des décisions de ces derniers. Plus l'environnement est pauvre, plus les «soins» deviennent importants afin de soutenir la survie, la croissance et le développement des enfants.

Le cadre conceptuel de l'UNICEF pour la nutrition a été conçu en 1990 et adopté à Rome en 1992 à la Conférence Internationale sur la Nutrition. Il reconnaît trois facteurs sous-tendant la survie, la croissance et le développement des enfants $[97,98]$. Les deux premiers sont la sécurité alimentaire au domicile et les services et l'environnement sanitaires. Le troisième élément de la triade se compose de la prise en charge globale (caring), «apport aux foyers familiaux et à la communauté de temps, d'attention et de soutien afin de satisfaire les besoins physiques, mentaux et sociaux de l'enfant en croissance et des autres membres du foyer». La théorie raffinée énoncée par Martin-Prevel [97] décrit les ressources de soins des foyers familiaux selon trois catégories: humaines (connaissances, croyances, éducation et santé physique et mentale de l'aidant), économiques (contrôle des revenus, charge de travail et temps) et organisationnelles (autres aidants et soutien de la communauté).

Martin-Prevel [97] a individualisé et priorisé les éléments spécifiques des soins. Il existe six catégories de pratiques de soins, comme mentionné dans le tableau 5 . En règle générale, la mère est supposée être la principale personne en charge de l'enfant. Comme on peut le voir, toutes les six sont absolument essentielles pour la santé des enfants à l'ère du VIH/sida. Les pratiques protègent tout d'abord la personne ayant l'enfant à sa charge, puis permettent la nutrition de la famille et la diminution des facteurs nocifs pour la santé présents dans l'environnement.
Les zones urbaines du sous-continent indien sont parmi les régions où l'épidémie de $\mathrm{VIH} /$ sida s'étend le plus rapidement. Il est important de reconnaître que l'état nutritionnel des enfants des quartiers pauvres est le pire de tous les groupes urbains et est même plus mauvais que la moyenne en zone rurale [99]. Cette situation est aggravée par l'absence de pratiques correctes de soins des enfants. De plus, tout comme dans le cas de la sécurité alimentaire, le contexte de pauvreté prédispose aux soins précaires des enfants et la charge additionnelle de l'épidémie de sida fait peser des contraintes sévères sur une situation déjà fragile.

\section{Orphelins et aides non parentaux}

Les orphelins sont une conséquence malheureuse du VIH/ sida symptomatique et fatal se répandant chez les adultes. Il s'agit d'un facteur majeur de risque de mauvaise santé et de sous-nutrition des enfants dans une communauté. Dans leurs commentaires sur les enfants devenus orphelins en raison du sida, Shetty et Powell [100] écrivent: «Au plan international, la crise des orphelins due à la pandémie d'infection à virus de l'immunodéficience humaine/syndrome d'immunodéficience acquise (VIH/sida) demeure un problème grave aux conséquences sociales à long terme. A la fin de 2001, des estimations indiquaient que 14 millions d'enfants au plan mondial avaient perdu leur mère ou leurs deux parents en raison d'un sida ou de causes apparentées. L’Afrique sub-saharienne est la plus sévèrement affectée, ayant plus de $80 \%$ des enfants devenus orphelins en raison du sida». Sans les soins de leurs parents ou d'un aidant appointé, les enfants sont probablement confrontés à des risques considérables de malnutrition, de mauvaise santé, de scolarisation inadéquate, de migration, de perte de domicile et d'abus [100].

Selon des estimations, le nombre d'enfants actuellement orphelins en Ouganda principalement en raison du sida est de deux millions [101]. Pour la partie nord du pays, on soutient que les transformations consécutives des pratiques d'adoption doivent être historiquement comprises au travers des effets des conflits armés et du déracinement de l'économie locale pastorale basée sur le coton survenus depuis la fin des années 1970 [101]. Ces processus ont conjointement produit une marginalisation économique spectaculaire aux conséquences fortement perturbantes pour les orphelins et leurs aidants. Lors d'une étude anthropologique menée dans le Kenya rural, Nyambedha et coll. [102] ont observé que l'inaptitude des foyers hébergeant des orphelins à régler les frais scolaires était la limitation perçue la plus pressante, bien que l'insuffisance des aliments, des soins médicaux et des vêtements ait également été important. Les systèmes traditionnels d'entraide basés sur la parenté contribuent de façon majeure à l'hébergement des orphelins, bien que les ressources soient loin d'être suffisantes. Des observations effectuées dans le sud de l'Afrique montrent que la seule présence des parents réduit de 39 à $21 \%$ le risque d'insuffisance pondérale de l'enfant; ce risque n'est que de $10 \%$ chez les enfants dont les deux parents sont vivants [12]. 


\section{Réformer les attitudes et les pratiques de soins}

Il semble prétentieux à certains que des professionnels aux conceptions occidentales et résidant dans des pays riches se permettent de critiquer et d'entreprendre de «réformer» des attitudes et pratiques concernant les soins des enfants dans des sociétés non occidentales économiquement faibles [103]. Décider quelles sont les «bonnes» pratiques traditionnelles de soins à conserver et celles qu'il faudrait «améliorer» semblerait être le sommet de la prétention. Ces personnes appelleraient à la constitution d'une couverture respectant les approches traditionnelles des soins qui, selon eux, sont «testées et avérées», le produit de siècles d'évolution et d'adaptation sociale incorporant la sagesse culturelle. Qui sont l'UNICEF, les anthropologues ou les scientifiques pour imposer un nouveau programme de soins à une communauté?

L'évolution culturelle des sociétés a donné naissance aux pratiques traditionnelles de soins des enfants, et, de ce fait, les impératifs de l'évolution sont pertinents pour mieux comprendre leurs origines et conséquences pour la santé des enfants. Selon la théorie de Darwin, l'intention de l'évolution n'est pas que tous ceux qui sont nés survivent. Les terrains disponibles pour les clans nomades ne pouvaient nourrir qu'un nombre restreint de cueilleurs et de chasseurs, de sorte que, du point de vue de l'évolution, la stabilité numérique, plutôt que l'expansion, était favorable à la survie des tribus, et donc de l'espèce humaine. Bien entendu, pour la survie, les sujets les plus résistants et les mieux adaptés à un environnement où les difficultés étaient abondantes étaient les plus appréciés pour perpétuer les lignées héréditaires des clans.

En suivant cette logique de l'évolution, les pratiques traditionnelles de soins ne doivent pas être comprises comme nécessairement adaptées pour la survie de tous les sujets. Cette situation aurait aboutit à une surpopulation des étendues territoriales. De fait, les soins traditionnels peuvent avoir un aspect de défis pour la survie de l'enfant, défis qui produisent et sélectionnent l'adaptation constitutionnelle innée de certains enfants leur permettant de surmonter les dangers de l'environnement. Ceux qui échouent aux tests ouvrent la voie à ceux qui les réussissent, dans le classique schéma de survie pour la reproduction du mandat le mieux adapté de la biologie de l'évolution.

Dans la mesure où l'éthique sociale contemporaine repose sur le respect absolu du droit de tous les enfants à survivre et à se développer, tout impératif d'évolution présent dans les pratiques de soins doit être remplacé par un impératif humanitaire qui, de fait, maximalise la survie de tous les sujets. La justification de la réforme des pratiques traditionnelles de soins est précisément d'assurer que les comportements sont expressément dirigés vers la protection de la santé de tous. Les enfants infectés par le VIH peuvent, de fait, idéalement nécessiter des pratiques de soins différentes de celles s'adressant aux enfants non infectés afin de mieux éliminer les risques environnementaux qui menaceraient leur santé et mettraient leur survie en péril.

En sus d'une pauvreté endémique et d'une limitation des ressources, les interactions de l'aidant et les pratiques de soins sur- viennent dans un contexte de pratiques plus adéquates et souvent nouvelles à introduire. La génération parentale ayant été décimée, les jeunes enfants doivent souvent être pris en charge par des frères et sœurs plus âgés ou leurs grands-parents. Ces derniers peuvent être les partisans les plus farouches des pratiques traditionnelles de soins des enfants ayant un impact davantage sélectif qu'assuré sur la survie; il s'avérerait probablement plus difficile de modifier les conceptions traditionnelles des grands-parents. Les frères et sœurs plus âgés n'ont qu'une expérience minime des soins et représenteraient une ardoise vierge sur laquelle inscrire de nouvelles attitudes et comportements. Mais le manque d'années et d'expérience parentale ne permet pas de leur confier facilement les soins de frères et sœurs plus jeunes. Ainsi, en raison de la maladie ou de l'absence des parents, les soins destinés à favoriser la bonne santé de l'enfant reposent sur la moins sûre des bases dans le contexte de l'infection endémique à VIH.

Les soins des enfants souffrent également des contraintes excessives s'exerçant sur le travail humain et dues au VIH/sida. Gillespie et coll. [62] ont présenté une analyse du coût global du $\mathrm{VIH} /$ sida. A un niveau global, l'infection à VIH/sida était la $28^{8^{\mathrm{m} e}}$ cause de perte d'années de vie corrigée en fonction de l'invalidité (DALY) en 1990, et devrait être la $10^{\text {ème }}$ en 2020 . Le VIH/sida devrait être la troisième cause de DALY en 2020 en Afrique sub-saharienne (soit une progression depuis la $7^{\text {ème }}$ place en 1990) ainsi qu'en Inde (un accroissement colossal). Les auteurs expliquent ensuite que les pleins effets sur le travail ne sont pas adéquatement représentés par ces chiffres, car le travail des sujets en bonne santé devant se livrer à d'autres activités en raison du VIH/sida, telles que les soins des sujets infectés et affectés n'est pas inclus. White et Robinson [104] ont indiqué que l'impact mesuré sur les rapports de dépendance des foyers familiaux n'était pas concluant. Cette situation peut être due aux mécanismes de résolution habituelle des problèmes des communautés ou des familles, qui comportent l'envoi d'enfants à d'autres domiciles par l'intermédiaire de réseaux familiaux ou informels non familiaux, tout en faisant travailler les plus jeunes pour les aider à produire. Le coût de ces déplacements de travail peut entraîner des soins plus médiocres aux enfants ainsi qu'une augmentation du risque de transmission du VIH. La prise en charge des enfants en terme d'éducation de base est également réduite à néant, car les enfants quittent l'école afin d’aider les familles à soigner les personnes malades et à maintenir leurs revenus. Cette dernière situation se traduit souvent par des comportements à risque, qui perpétuent par la suite la dissémination du VIH.

Il est peu probable que de nouvelles ressources externes destinées aux soins puissent être directement mises à la disposition de communautés déjà indigentes, et une approche de «déviance positive» des soins a donc été proposée [105-107] et explorée. Une enquête de déviance positive identifie des comportements et modèles d'aidants et/ou de foyers peu fréquents dont les conséquences sont positives pour les enfants dans une communauté [106]. Ces comportements sont appelés pratiques de déviance positive. Il est supposé que les programmes favorisant 
des pratiques de déviance positive ne se heurteront probablement pas à des contraintes de recherche. Au niveau de la communauté, les programmes de déviance positive doivent inclure une planification, une orientation de la communauté, une analyse de la situation, des enquêtes spécifiques et les commentaires de la communauté quant à la planification des actions [106]. Un exemple provient du Pakistan rural, où des pratiques de soins des nouveau-nés allant de l'allaitement exclusif à la protection contre la chaleur et à l'hygiène ont été identifiées comme des pratiques déviantes positives et promues par la suite [106]. Un autre provient du nord du Vietnam, où la qualité de l'assistance alimentaire aux jeunes enfants a été abordée [107]. Le programme a observé qu'une alimentation proposée de façon interactive aux enfants, impliquant une verbalisation et un encouragement approprié des enfants au cours de la seconde année de leur vie, était le comportement positif entraînant l'acceptation d'aliments et l'amélioration de l'état de la santé et de la nutrition de l'enfant.

Les facteurs fusionnant de façon spécifique et expresse les soins et la compétence des aidants dans l'épidémie de VIH/sida commencent à apparaître $[105,107,108]$. Lapping et coll. [105] ont partagé leur expérience précoce de l'approche de déviance positive dans le présent numéro (VIH/sida et sécurité alimentaire). L'ensemble des auteurs considère que leur intervention de déviance positive accélère le changement en catalysant les processus de mobilisation, de prise de conscience, de résolution des problèmes, de motivation pour des changements de comportement, de défense et l'adoption réelle de nouveaux comportements dans la communauté. Les auteurs admettent toutefois qu'ils doivent encore quantifier tout bénéfice pour la sécurité alimentaire et les conséquences sanitaires imputables à l'approche de déviance positive [107]. Deux expériences ont été publiées et concernent l'est du Kenya, où le programme Lea Toto Kangemi Outreach soutient des familles élevant des enfants séropositifs pour le VIH $[108,109]$ et dont un grand nombre sont orphelins ou vont l'être de façon imminente. Dans cette enquête, une absence de stigmatisation s'est avérée un facteur de meilleure connaissance des soins. Les membres de la communauté qui étaient les plus jeunes, célibataires et les moins instruites ont subi une stigmatisation plus importante [108]. A l'inverse une moindre stigmatisation était associée à une meilleure connaissance des soins [109]. Les conséquences pratiques de cette situation appelleraient à des efforts destinés à diminuer la stigmatisation des foyers où vivent des personnes infectées par le VIH et donc à améliorer les pratiques et connaissances des soins pour de meilleures conséquences pour les enfants.

L'accumulation des facteurs d'isolement dus à un faible revenu, à la localisation géographique et à la stigmatisation du $\mathrm{VIH} /$ sida pèse sur les moyens d'améliorer la santé des enfants. Les stratégies susmentionnées pour un soutien aux soins reposent ici encore sur la planification et le développement locaux de ressources. Toutefois, dans la mesure où les communautés atteintes peuvent se manifester, la demande du respect de leur droit à la santé par les autorités municipales, étatiques, nationales et internationales est une approche complémentaire. Un exemple de cette situation provient des «favelas» pauvres de Rio de Janeiro, Brésil, où œuvre une société civile, le Centre pour la Promotion de la Santé [110]. Ce mouvement communautaire a créé un sentiment «d'appropriation» des actions sociales, ciblant les déterminants de la vulnérabilité locale tout en suscitant une prise de conscience des droits à la santé.

\section{Conclusions et projections}

Si la pauvreté ne constituait pas un contexte et une caractéristique si fondamentaux de l'épidémie de VIH/sida, les problèmes nutritionnels et sanitaires ne seraient pas si importants. Dans un monde qui doit encore éliminer la pauvreté extrême, la recette semblerait être un immense bon permettant de franchir l'obstacle, dans la mesure où «le développement durable nécessite des modifications politiques, économiques et sociales incluant un don de pouvoir aux personnes injustement privées de leur droits, un élargissement de l'accès aux biens et autres ressources, un rétrécissement du fossé entre riches et pauvres et un ajustement des profils de la consommation afin de renforcer une bonne intendance de la nature» [111].

Avec la nécessité difficile à assurer d'un développement durable, le VIH/sida représente un défi immense et croissant pour la protection de la santé publique mondiale, un drainage des ressources et une cause de souffrance et de stigmatisation colossales. Son ère a débuté voici un quart de siècle. La présente analyse a montré les origines sociales des soins médicaux et des problèmes nutritionnels. Avec sa longue période de latence avant la survenue de manifestations pathologiques et la progression vers le décès, notre aptitude à comprendre les diverses demandes sanitaires et sociales qu'il suscite et à y répondre a été compromise.

La pandémie de VIH/sida n'existe que depuis un quart de siècle et ses aspects épidémiologiques et pharmacologiques évoluent et se transforment. Nous avons mobilisé ici un immense ensemble de données de la littérature démontrant le rôle capital de l'alimentation, de la nutrition et de la sécurité alimentaire dans les efforts destinés à atténuer les effets de l'infection. L'expérience et divers arguments nous ont cependant montré les limites du développement d'interventions «basées sur des données probantes» en tant que seules approches destinées à pallier les échecs des soins des enfants et à combler les brèches béantes de l'insécurité alimentaire. Les lacunes de nos connaissances ont été identifiées, soulignant des besoins prioritaires de recherches supplémentaires afin de continuer la lutte contre l'infection. Le tableau 6 mentionne certaines des questions opérationnelles de recherche identifiées par le groupe d'experts consultants de l'OMS [74]. Les assauts les plus sévères du VIH/sida se produisent cependant dans les contextes les plus dépourvus de ressources, dans lesquels une approche adéquate des besoins en matière de prévention, de lutte contre la maladie et de soins est encore un luxe. Les ressources destinées aux recherches entrent directement en compétition avec celles consacrées aux interventions quand les fonds disponibles sont limités. 
Malgré un effort d'identification des lacunes des connaissances et des priorités à des fins de nouvelles recherches, le groupe de l'OMS a conclu que de nombreuses actions peuvent et doivent être entreprises afin d'améliorer la santé, la nutrition et la qualité de vie des personnes vivant avec le VIH/sida [74]. De ce fait, et comme la plupart des travailleurs à l'échelon des programmes $[43,96]$ et la plupart des scientifiques qui conseillent et informent les politiques $[62,89,92]$ l'ont préconisé, il est plus important de rassembler l'expérience et de raffiner les pratiques dans le contexte de la formulation d'actions immédiates et continues afin de renforcer la sécurité alimentaire. Deux des principes majeurs énoncés dans l'ensemble du présent numéro sont les suivants: (1) une approche totale et holistique des problèmes sous-jacents allant au-delà des personnes spécifiquement infectées par le VIH et (2) des travaux fondamentaux au niveau des communautés, en les consultant, en les impliquant et en leur donnant des responsabilités durables.

En ce qui concerne le lien entre les soins et la santé des enfants, l'épidémie de VIH/sida suscite un grand nombre de problèmes identiques à ceux affectant la sécurité alimentaire. Il existe une perturbation de la stabilité du foyer familial, une perte de revenus et de ressources accumulées et l'émergence d'aidants trop jeunes et trop peu expérimentés ou trop âgés et débilités pour assurer les soins appropriés. Les pratiques traditionnelles de soins dans les sociétés n'assureront cependant pas toujours la survie de tous les enfants. Chez ceux qui sont dénutris et immunocompromis, des agents pathogènes transmis par les aliments et l'eau à la suite de pratiques sanitaires inadéquates peuvent être potentiellement fatals. Moss et coll. [112] ont préconisé «des recommandations basées sur des données probantes et localement adaptées pour les soins des enfants», ce qui soulève encore la question de savoir comment partager les ressources entre la fourniture et l'étude de services.

En l'absence du luxe qui consisterait à financer une recherche exploratoire dédiée concernant les lacunes persistantes de nos connaissances fondamentales et pratiques, le second point peut être au moins abordé dans le contexte d'une expérience transmise sur le terrain. Comme l'ont montré des réunions telles que l'African Forum [96], une notion générale de ce qui fonctionne, de ce qui fonctionne bien et de ce qui ne fonctionne pas peut être produite par l'expérience collective de la communauté à des travailleurs sur le terrain. Ladaptation des interventions au contexte et aux réalités changeantes du terrain est considérée comme une vertu positive. L'accent est actuellement davantage mis sur des programmes intégrés de lutte contre le VIH/sida et de sécurité alimentaire et nutritionnelle et d'interventions dans le même domaine favorisant la sécurité alimentaire et la santé des enfants.

La réalité sur le terrain dans les communautés dont les travailleurs et les résidents sont insuffisamment nombreux, souséquipés, manquent de ressources et sont confrontés à la lutte quotidienne pour les aliments et les soins est, de fait, celle de mécanismes de résolution des problèmes soumis à des contraintes extrêmes et prêts à s'effondrer. Nous devons toutefois avoir
Tableau 6. Sélection de questions pertinentes auxquelles des recherches devront répondre afin de combler les lacunes persistantes des connaissances sur la relation entre sécurité alimentaire et $\mathrm{VIH} / \mathrm{sida}$

1 Quels sont les effets de l'amélioration de la technologie alimentaire au foyer familial, des conseils diététiques et de la fourniture d'aliments au cours d'actions de soins de la communauté sur la récupération nutritionnelle, la progression de la maladie et la qualité de vie?

2 Quelles sont les actions des programmes de soutien alimentaire et nutritionnel à modifier en raison du VIH/sida? Par exemple, faut-il modifier la taille ou la composition des rations pour la population affectée par le VIH? Quels sont les critères du ciblage d'aliments destinés à tempérer les effets du VIH/sida?

3 Quelles sont les interventions nutritionnelles efficaces pour la sécurité alimentaire afin d'atténuer l'impact nutritionnel du VIH dû à une réduction de la productivité agricole et/ou des capacités de soins globaux?

4 Quel est l'impact du traitement antirétroviral dans des populations malnutries? Le statut nutritionnel affecte-t-il l'efficacité du traitement et le risque ou la sévérité des événements indésirables qui lui sont associés? Des interventions nutritionnelles, particulièrement dans les populations sous-nutries et chez les mères allaitantes, associées au traitement antirétroviral entraîneraient-elles une évolution clinique plus favorable?

Extrait de l'OMS [70].

une vision et des projections allant au-delà du statut quo. Si nous acceptons que la sécurité alimentaire relève généralement d'un concept quantitatif consistant à disposer de suffisamment d'aliments pour se nourrir et éviter la faim et la malnutrition, d'autres aspects d'une alimentation de qualité doivent émerger dans un contexte tant à court qu'à plus long terme pour les personnes vivant avec le VIH/sida [113]. La sécurité alimentaire, en d'autres termes le fait de disposer d'aliments non contaminés, est importante dans l'immédiat car les maladies transmises par les aliments peuvent être plus dévastatrices pour les sujets immunocompromis. De plus, comme discuté ailleurs en termes de surnutrition, l'avènement d'un traitement accessible à certaines populations séropositives suscite la possibilité d'une survie à long terme et de domaines concernant la santé, également à long terme. Un régime alimentaire sain, visant à réduire le risque de maladie non transmissible, doit être envisagé à titre de raffinement final au-delà de l'abondance et de la sûreté des aliments, en accord avec les sages commentaires de Gopalan [47]: «La sécurité de la nutrition au foyer familial signifie plus que d'éviter une sous-alimentation chronique. Les décisionnaires des pays en développement doivent se fixer, comme objectif au cours du siècle prochain, l'obtenir une nutrition adéquate plutôt que simplement de la survie». Il s'agit là d'une vision plus optimiste pour toutes les communautés, dont celles vivant avec le VIH/sida. 


\section{Références}

1 Gottlieb MS, Schanker HM, Fan PT, Weisman JT: Pneumocystis pneumonia - Los Angeles. MMWR 1981;30:1-3.

$>2$ Heeney JL, Dalgleish AG, Weiss RA: Origins of HIV and the evolution of resistance to AIDS. Science 2006;313:462-466.

$\checkmark 3$ Piot P, Bartos M, Ghys PD, et al: The global impact of HIV/AIDS. Nature 2001;410:968973.

4 Shears P: Cholera. Ann Trop Med Parasitol 1994;88:109-122.

$>5$ Guerrant RL, Carneiro-Filho BA, Dillingham RA: Cholera, diarrhea, and oral rehydration therapy: triumph and indictment. Clin Infect Dis 2003;37:398-405.

6 Henderson DA: Smallpox eradication. Public Health Rep 1980;95:422-426.

7 Zlotnik H: Demographic trends; in Caballero B, Popkin BM (eds): The Nutrition Transition: Diet and Disease in the Developing World. London, Academic Press, 2002, pp 71-107.

8 Rutengwe RM: Identifying strategic interventions for improving household food and nutrition security in an urban informal settlement, South Africa. Asia Pac J Clin Nutr 2004;13(suppl):S169.

$>9$ Walker N., Schwartländer J: Meeting international goals in child survival and HIV/ AIDS. Lancet 2002;360:284-289.

10 Hunter S, Williamson J: Children on the Brink 2000: Executive Summary - Updated Estimates and Recommendations for Intervention. The Synergy Project 2000. Washington, USAID, 2000, pp 1-32.

$\checkmark 11$ Somerville MA, Orkin AJ: Human rights, discrimination and AIDS: concepts and issues. AIDS 1989;3(suppl 1):S283-S287.

12 Hecht R, Alban A, Taylor K, et al: Putting it together: AIDS and the millennium development goals. PLoS Med 2006;3:e455.

13 Haddad L: No longer off the menu: the welcome re-emergence of food on the nutrition agenda. Forum Nutr 2003;56:383-384.

14 The President's Emergency Plan for AIDS Relief. Report on Food and Nutrition for People Living with HIV/AIDS. Washington, Office of the US Global AIDS Coordinator US Department of State, 2006

$\checkmark 15$ Scrimshaw NS, Taylor CE, Gordon JE: Interactions of nutrition and infection. Am J Med Sci 1959;237:367-403.

-16 Scrimshaw NS, Taylor CE, Gordon JE: Interactions of nutrition and infection. Monog Ser World Health Organ 1968;57:3-329.

17 Keusch GT, Farthing MJG: Nutrition and infection. Annu Rev Nutr 1986;6:131-154.

18 Scrimshaw NS, SanGiovanni JP: Synergism of nutrition, infection, and immunity: an overview. Am J Clin Nutr 1997;66:464S$477 \mathrm{~S}$.
19 Wanke CA, Silva M, Knox TA, et al: Weight loss and wasting remain common complications in individuals infected with human immunodeficiency virus in the era of highly active antiretroviral therapy. Clin Infect Dis 2000;31:803-805.

20 Ungar BLP, Ward DJ, Fayer R, Quinn CA: Cessation of cryptosporidium-associated diarrhea in an acquired immunodeficiency syndrome patient after treatment with hyperimmune bovine colostrum. Gastroenterology 1990;98:486-489.

21 Saini A, Nasser AS, Stewart CE: Waste management - cytokines, growth factors and cachexia. Cytokine Growth Factor Rev 2006;7: 475-486.

-22 MacDonald KS, Malonza I, Chen DK, et al: Vitamin A and risk of HIV-1 seroconversion among Kenyan men with genital ulcers. AIDS 2001;15:635-639.

23 Semba RD, Neville MC: Breast-feeding, mastitis, and HIV transmission: nutritional implications. Nutr Rev 1999;57:146-153.

24 Fawzi WW: Nutritional factors and vertical transmission of HIV-1: epidemiology and potential mechanisms. Ann NY Acad Sci 2000;918:99-114.

25 Dreyfuss ML, Fawzi WW: Micronutrients and vertical transmission of HIV-1. Am J Clin Nutr 2002;75:959-970.

26 Downs JH, Cooper PA: HIV and lactation. Ann Nestlé [Engl] 2007;65:29-38.

27 Tang AM, Graham NM, Kirby AJ, et al: Dietary micronutrient intake and risk progression to acquired immunodeficiency syndrome (AIDS) in human immunodeficiency virus type (HIV-1)-infected homosexual men. Am J Epidemiol 1993;138:937-951.

28 Tang AM, Graham NM, Saah AJ: Effects of micronutrient intake on survival in human immunodeficiency virus type I infection. Am J Epidemiol 1996;143:1244-1256.

29 Tang A, Graham N, Semba R, Saah A: Association between serum vitamin A and E levels and HIV-1 disease progression. AIDS 1997;11:613-620.

30 Baum MK, Shor-Posner G, Lu Y, et al: Micronutrients and HIV-1 disease progression. AIDS 1995;9:1051-1056.

31 Mehta S, Finkelstein JL, Fawzi W: Nutritional interventions in HIV-infected breastfeeding women. Ann Nestlé [Engl] 2007;65:3948.

32 Beck MA, Kolbeck PC, Shi Q, et al: Increased virulence of a human enterovirus (coxsackievirus B3) in selenium-deficient mice. J Infect Dis 1994;170:351-357.

33 Beck MA, Handy J, Levander OA: Host nutritional status: the neglected virulence factor. Trends Microbiol 2004;12:417-423.

34 Nelson HK, Shi Q, Van Dael P, et al: Host nutritional selenium status as a driving force for influenza virus mutations. FASEB J 2001; 15:1846-1848.
35 Beck MA, Nelson HK, Shi Q, et al: Selenium deficiency increases the pathology of in influenza virus infection. FASEB J 2001;15: 1481-1486.

-36 Sazawal S, Black RE, Ramsan M, et al: Effects of routine prophylactic supplementation with iron and folic acid on admission to hospital and mortality in preschool children in a high malaria transmission setting: community-based, randomised, placebo-controlled trial. Lancet 2006;367:133-143.

37 Weinberg ED: Iron withholding: a defense against viral infections. Biometals 1996;9: 393-399.

38 Bobat R, Coovadia H, Stephen C, et al: Safety and efficacy of zinc supplementation for children with HIV-1 infection in South Africa: a randomised double-blind placebocontrolled trial. Lancet 2006;367:814-815.

-39 Olsen A, Mwaniki D, Krarup H, Friis H Low-dose iron supplementation does not increase HIV-1 load. J Acquir Immune Defic Syndr 2004;36:637-638.

40 Friis $\mathrm{H}$ (ed): Micronutrients and HIV Infection. Boca Raton, CRC Press, 2002.

41 Piot P: Keynote Address. Nutrition and HIV/ AIDS. Nutrition Policy Paper No. 20. SubCommittee on Nutrition. Geneva, SCN 2001, pp 7-10.

42 Whiteside A, Barnett T, George G, Van Niekerk AA: Through a glass, darkly: data and uncertainty in the AIDS debate. Developing World Bioeth 2003;3:49-76.

43 Tabi M, Vogel RL: Nutritional counselling: an intervention for HIV-positive patients. J Adv Nurs 2006;54:676-682.

44 Fields-Gardner C, Fergusson P; American Dietetic Association; Dietitians of Canada: Position of the American Dietetic Association and Dietitians of Canada: nutrition intervention in the care of persons with human immunodeficiency virus infection. J Am Diet Assoc 2004;104:1425-1441.

45 Tontisirin K, Bhattacharjee L: Food security and nutrition - a household perspective. Forum Nutr 2003;56:382-383.

46 Casey PH, Simpson PM, Gossett JM, et al: The association of child and household food insecurity with childhood overweight status. Pediatrics 2006;118:e1406-e1413.

47 Gopalan C: Achieving household nutrition security in societies in transition: an overview. Asia Pac J Clin Nutr 2001;10(suppl): S4-S12.

48 Kendall A, Olson CM, Frongillo EA Jr: Validation of the Radimer/Cornell measures of hunger and food insecurity. J Nutr 1995;125: 2793-2801.

49 Frongillo EA Jr, Rauschenbach BS, Olson $\mathrm{CM}$, et al: Questionnaire-based measures are valid for the identification of rural households with hunger and food insecurity. J Nutr 1997;127:699-705. 
50 Onyango AW: Dietary diversity, child nutrition and health in contemporary African communities. Comp Biochem Physiol A Mol Integr Physiol 2003;136:61-69.

-51 Keenan DP, Olson C, Hersey JC, Parmer SM: Measures of food insecurity/security. J Nutr Educ 2001;33(suppl 1):S49-S58.

52 Rose D: Economic determinants and dietary consequences of food insecurity in the United States. J Nutr 1999;129(suppl):517S$520 \mathrm{~S}$.

53 Shariff ZM, Khor GL: Obesity and household food insecurity: evidence from a sample of rural households in Malaysia. Eur J Clin Nutr 2005;59:1049-1058.

54 Webb P, Coates J, Frongillo EA, et al: Measuring household food insecurity: why it's so important and yet so difficult to do. J Nutr 2006;136:1404S-1408S.

55 Nyindo M: Complementary factors contributing to the rapid spread of HIV-I in sub-Saharan Africa: a review. East Afr Med J 2005; 82:40-46.

56 Mhalu FS: Burden of diseases in poor resource countries: meeting the challenges of combating HIV/AIDS, tuberculosis and malaria. Tanzan Health Res Bull 2005;7:179184.

57 Chopra M, Darnton-Hill I: Responding to the crisis in sub-Saharan Africa: the role of nutrition. Public Health Nutr 2006;9:544550.

58 Watts J: Targets now set by G8 countries to reduce 'diseases of poverty'. Lancet 2000; 356:408.

59 Rukuni M: Africa: addressing growing threats to food security. J Nutr;132:3443S3448S.

60 Saasa OS: HIV/AIDS and Development Unsolved Challenges for Africa. Nutrition and HIV/AIDS. Nutrition Policy Paper No. 20. SubCommittee on Nutrition. Geneva, SCN, 2001, pp 19-27.

61 Hunter SS, Bulirwa E, Kisseka E: AIDS and agricultural production. Report of a land utilization survey, Masaka and Rakai districts of Uganda. Land Use Policy 1993;10: 241-258.

62 Gillespie S, Haddad L, Jackson R: HIV/AIDS, food and nutrition security: impacts and actions. 28th Session of the ACC/SCN Symposium on Nutrition and HIV/AIDS, Nairobi, 2001.

63 Cummings B, Mengistu M, Negash W, et al: Barriers to and facilitators for female participation in an HIV prevention project in rural Ethiopia: findings from a qualitative evaluation. Cult Health Sex 2006;8:251-266.

64 Hindin MJ: Women's input into household decisions and their nutritional status in three resource-constrained settings. Public Health Nutr 2006;9:485-493.

-65 Kruger A, Lemke S, Phometsi M, et al: Poverty and household food security of black South African farm workers: the legacy of social inequalities. Public Health Nutr 2006;9: 830-836.
66 Thomas F: Stigma, fatigue and social breakdown: exploring the impacts of HIV/AIDS on patient and carer well-being in the Caprivi Region, Namibia. Soc Sci Med 2006;63: 3174-3187.

67 Thomas BE, Rehman F, Suryanarayanan D, et al: How stigmatizing is stigma in the life of people living with HIV: a study on HIV positive individuals from Chennai, South India. AIDS Care 2005; 17:795-801.

68 Mawar N, Saha S, Pandit A, Mahajan U: The third phase of HIV pandemic: social consequences of HIV/AIDS stigma and discrimination and future needs. Indian J Med Res 2005; 122:471-484.

69 Reidpath DD, Brijnath B, Chan KY: An Asia Pacific six-country study on HIV-related discrimination: introduction. AIDS Care 2005;17(suppl 2):S117-S127.

70 VanLandingham MJ, Im-Em W, Saengtienchai C: Community reaction to persons with HIV/AIDS and their parents: an analysis of recent evidence from Thailand. J Health Soc Behav 2005;46:392-410.

71 Gillespie S, Haddad L, Jackson R: HIV/AIDS, Food and Nutrition Security: Impacts and Actions. Nutrition and HIV/AIDS. Nutrition Policy Paper No. 20. SubCommittee on Nutrition. Geneva, SCN, 2001, pp 31-45.

72 Wyss K, Hutton G, N'Diekhor Y: Costs attributable to AIDS at household level in Chad. AIDS Care 2004; 16:808-816.

73 Food and Nutrition Board, Institute of Medicine: Dietary Reference Intakes for Energy, Carbohydrate, Fiber, Fat, Fatty Acids, Cholesterol, Protein, and Amino Acids. Part 1, Summary and chapters 1-9. Washington, National Academy Press, 2002.

74 World Health Organization: Nutrient Requirements for People Living with HIB/ AIDS. Report of Technical Consultation. Geneva, WHO, 2003.

75 Manuela de Paoli M, Manongi R, Klepp KI: Are infant feeding options that are recommended for mothers with HIV acceptable, feasible, affordable, sustainable and safe? Pregnant women's perspectives. Public Health Nutr 2004;7:611-619.

76 Thior I, Lockman S, Smeaton LM, et al: Breastfeeding plus infant zidovudine prophylaxis for 6 months vs formula feeding plus infant zidovudine for 1 month to reduce mother-to-child HIV transmission in Botswana: a randomized trial: the Mashi Study. JAMA 2006;296:794-805.

77 Forrester JE, Tucker KL, Gorbach SL: Dietary intake and body mass index in HIVpositive and HIV-negative drug abusers of Hispanic ethnicity. Public Health Nutr 2004; 7:863-870

78 Paton NI, Sangeetha S, Earnest A, Bellamy R: The impact of malnutrition on survival and the CD4 cell response in HIV-infected patients starting antiretroviral therapy. HIV Med 2006;7:323-330.
79 Kim JH, Spiegelman D, Rimm E, Gorbach SL: The correlates of dietary intake along HIV-positive adults. Am J Clin Nutr 2001;74: 852-861.

80 Betsi NA, Koudou BG, Cisse G, et al: Effect of an armed conflict on human resources and health systems in Cote d'Ivoire: prevention of and care for people with HIV/AIDS. AIDS Care 2006;18:356-365.

-81 Spiegel PB: HIV/AIDS among conflict-affected and displaced populations: dispelling myths and taking action. Disasters 2004;28: 322-339.

- 82 Vorster HH, Venter CS, Wissing MP, Margetts $\mathrm{BM}$ : The nutrition and health transition in the North West Province of South Africa: a review of the THUSA (Transition and Health during Urbanisation of South Africans) study. Public Health Nutr 2005;8:480490

83 Bourne LT, Lambert EV, Steyn K: Where does the black population of South Africa stand on the nutrition transition? Public Health Nutr 2002;5:157-162.

84 Zimmet P: Epidemiology of diabetes mellitus and associated cardiovascular risk factors: focus on human immunodeficiency virus and psychiatric disorders. Am J Med 2005;118(suppl 2):3S-8S.

85 Amorosa V, Synnestvedt M, Gross R, et al: A tale of 2 epidemics: the intersection between obesity and HIV infection in Philadelphia. J Acquir Immune Defic Syndr 2005;39:557561.

86 Jaime PC, Florindo AA, Latorre MD, Segurado $\mathrm{AA}$ : Central obesity and dietary intake in HIV/AIDS patients. Rev Saude Publica 2006;40:634-640.

87 Rosegrant MW, Cline SA: Global food security: challenges and policies. Science 2003; 302:1917-1919.

- 88 Gregory PJ, Ingram JS, Brklacich M: Climate change and food security. Philos Trans R Soc Lond B Biol Sci 2005;360:2139-2148.

89 Gillespie S: AIDS, Poverty and Hunger: Challenges and Response. Food Policy Statement. Washington, International Food Policy Research Institute, 2006.

90 Gillespie S: Interventions and impacts: how HIV/AIDS interacts with food and nutrition security: an overview to volume 1 . Int Conf HIV/AIDS and Food and Nutrition Security, Durban, 2005.

91 Gillespie S: Policy and program response: responding to the Interactions between HIV/ AIDS an food and nutrition security: an overview to volume 2. Int Conf HIV/AIDS and Food and Nutrition Security, Durban, 2005.

92 Parley PG, Alston M, Piggett RR: Agricultural R\&D in the Developing World, Too Little Too Late? Washington, International Food Policy Research Institute, 2006.

93 Kadiyala S, Gillespie S: Rethinking food aid to fight AIDS. Food Nutr Bull 2004;25:271282.

infantile 
94 World Food Programme: Food Security, Food Aid and HIV/AIDS: Project Ideas to Address the HIV/AIDS Crisis. Rome, WFP, 2001.

95 Marchione TJ: Interactions with the recipient community in targeted food and nutrition programs. J Nutr 2005;135:886-889.

96 The African Forum 2006: An Integrated Response to the Dual Epidemic of HIV/ AIDS and Food Insecurity, Lukasa, Zambia, 2006.

-97 Martin-Prevel Y: 'Care' and public nutrition. Sante 2002;12:86-93.

98 Engle PL, Bentley M, Pelto G: The role of care in nutrition programmes: current research and a research agenda. Proc Nutr Soc 2000;59:25-35.

99 Ghosh S, Shah D: Nutritional problems in urban slum children. Indian Pediatr 2004; 41:682-696.

100 Shetty AK, Powell G: Children orphaned by AIDS: a global perspective. Semin Pediatr Infect Dis 2003;14:25-31.

101 Oleke C, Blystad A, Rekdal OB: 'When the obvious brother is not there': political and cultural contexts of the orphan challenge in northern Uganda. Soc Sci Med 2005;61: 2628-2638.
102 Nyambedha EO, Wandibba S, AagaardHansen J: Policy implications of the inadequate support systems for orphans in western Kenya. Health Policy 2001;58:83-96.

103 Engle PL, Pelto G, Bentley P: Care for nutrition and development. J Indian Med Assoc 2000;98:530-535.

104 White J, Robinson E: HIV/AIDS and Rural Livelihoods in Sub-Saharan Africa. Policy Series 6. Chatham, Natural Resources Institute, 2000.

105 Lapping K, Marsh DR, Rosenbaum J, et al: The positive deviance approach: challenges and opportunities for the future. Food Nutr Bull 2002;23(suppl):130-137.

106 Marsh DR, Sternin M, Khadduri R, et al: Identification of model newborn care practices through a positive deviance inquiry to guide behavior-change interventions in Haripur, Pakistan. Food Nutr Bull 2002; 23(suppl):109-118.

107 Ha PB, Bentley ME, Pachon H, et al: Caregiver styles of feeding and child acceptance of food in rural Viet Nam. Food Nutr Bull 2002;23(suppl):95-100.

108 Hamra M, Ross MW, Orrs M, D’Agostino A: Relationship between expressed HIV/ AIDS-related stigma and HIV-beliefs/ knowledge and behaviour in families of HIV infected children in Kenya. Trop Med Int Health 2006;11:513-527.
09 Hamra M, Ross MW, Karuri K, et al: The relationship between expressed HIV/AIDSrelated stigma and beliefs and knowledge about care and support of people living with AIDS in families caring for HIV-infected children in Kenya. AIDS Care 2005; 17:911-922.

110 Edmundo K, Guimaraes W, Vasconcelos Mdo S, et al: Network of communities in the fight against AIDS: local actions to address health inequities and promote health in Rio de Janeiro, Brazil. Promot Educ 2005;suppl 3:15-19.

111 Struble MB, Aomari LL: Position of the American Dietetic Association: addressing world hunger, malnutrition, and food insecurity. J Am Diet Assoc 2003;103:10461057.

112 Moss WJ, Ramakrishnan M, Storms D, et al: Child health in complex emergencies. Bull World Health Organ 2006;84:58-64.

113 Lobstein T: Food policies: a threat to health? Proc Nutr Soc 2002;61:579-585. 